\title{
Response of Total and Eddy Kinetic Energy to the Recent Spinup of the Beaufort Gyre
}

\author{
Heather Regan, CAmille Lique, and Claude TalandieR \\ Univ. Brest, CNRS, IRD, Ifremer, Laboratoire d'Océanographie Physique et Spatiale, IUEM, Brest, France \\ GianluCA Meneghello \\ Department of Earth, Atmospheric and Planetary Sciences, Massachusetts Institute of Technology, \\ Cambridge, Massachusetts
}

(Manuscript received 23 September 2019, in final form 26 November 2019)

\begin{abstract}
The Beaufort Gyre in the Arctic Ocean has spun up over the past two decades in response to changes of the wind forcing and sea ice conditions, accumulating a significant amount of freshwater. Here a simulation performed with a high-resolution, eddy-resolving model is analyzed in order to provide a detailed description of the total and eddy kinetic energy and their response to this spinup of the gyre. On average, and in contrast to the typical open ocean conditions, the levels of mean and eddy kinetic energy are of the same order of magnitude, and the eddy kinetic energy is only intensified along the boundary and in the subsurface. In response to the strong anomalous atmospheric conditions in 2007, the gyre spins up and the mean kinetic energy almost doubles, while the eddy kinetic energy does not increase significantly for a long time period. This is because the isopycnals are able to flatten and the gyre expands outwards, reducing the potential for baroclinic instability. These results have implications for understanding the mechanisms at play for equilibrating the Beaufort Gyre and the variability and future changes of the Arctic freshwater system.
\end{abstract}

\section{Introduction}

The Beaufort Gyre is an anticyclonic upper-ocean circulation feature that is the largest reservoir of freshwater in the Arctic (Haine et al. 2015; Carmack et al. 2016). Variability of freshwater export from the Arctic has the potential to influence the North Atlantic circulation and climate (Jahn and Holland 2013), for example, through contributing to Great Salinity Anomalies there (e.g., Belkin et al. 1998; Dickson et al. 1988), and affecting deep water formation (Arzel et al. 2008). The potential role of the gyre freshwater reservoir in modulating this export has motivated the recent effort to pin down the functioning of the Beaufort Gyre. This is particularly timely as we know the gyre is not in steady state. Satellite altimetry has indicated that the gyre has spun up during the 2000s (Giles et al. 2012), with hydrographic observations demonstrating that there was an associated increase in freshwater content of over $5400 \mathrm{~km}^{3}$ (around one-third of the content in

Corresponding author: Heather Regan, heather.regan@ifremer.fr
2003) between 2003 and 2010 (Krishfield et al. 2014). Characterization of the gyre from recent satellite observations of sea surface height (SSH) has indicated a gyre expansion at a rate of $53000 \mathrm{~km}^{2} \mathrm{yr}^{-1}$ toward the northwest from 2003 to 2014, resulting in the 2014 annual-mean gyre being almost double its 2003 area, with elevated gyre intensity between 2008 and 2012 (Regan et al. 2019).

Our current understanding of Beaufort Gyre dynamics mostly comes from simple process models (Davis et al. 2014; Lique et al. 2015; Manucharyan and Spall 2016; Meneghello et al. 2018a; Doddridge et al. 2019) and can be summarized as a three-way balance. At the surface, winds associated with the anticyclonic Beaufort Sea high drive Ekman pumping, and its resulting intensity is largely determined by the difference between the ice and ocean surface velocities (a process known as the ice-ocean governor; Meneghello et al. 2018b). The remaining input of energy induces downwelling and deepening of the halocline, which, in simple process models, is balanced by an eddy flux acting to flatten the isopycnals and stabilize the gyre 
(e.g., Manucharyan and Spall 2016). This balance is thought to occur on a long time scale (from a few years to a few decades; Doddridge et al. 2019; Johnson et al. 2018; Manucharyan et al. 2017) and suggests a link between small scale features and changes to the large scale circulation. The focus of this paper is to investigate the validity of the three-way balance in a realistic model, and in particular to quantify the response of the total and eddy kinetic energy to the recent spinup of the gyre.

Based on observations from a limited amount of temperature and salinity profiles collected by ice-tethered profilers (ITPs; Toole et al. 2011), Zhao et al. (2016) found that the number of eddies within the western Canada Basin increased in 2013-14 compared to the previous decade, and they hypothesized that this increase might be the consequence of the gyre spinup, resulting from more active baroclinic instability of the Beaufort Gyre. Moreover, the gyre changes could increase the number of eddies since expansion could increase interactions with shelf waters, boundary currents and topography (Zhao et al. 2016), although the presence of a continental slope may also help to stabilize the gyre, impeding the development of baroclinic instability at the edge of the gyre, and thus eddy generation, instead deepening the halocline (Manucharyan and Isachsen 2019). Therefore, determining the response of the eddy field to a gyre spinup is nontrivial. This has not been done before, largely because state-of-the-art numerical simulations do not resolve the small Rossby radius in the Arctic ( $\sim 10 \mathrm{~km}$; Nurser and Bacon 2014) and thus the evolution of the eddy field in the Arctic remains largely unknown.

Arctic eddies are generated from a variety of mechanisms and on different scales, and their presence was discussed in the literature before their role for Beaufort Gyre dynamics was established. Eddies were first observed in the Canada Basin in the 1970s (Newton et al. 1974; Manley and Hunkins 1985). They serve to transport heat and salt (Hunkins 1981), and can play an important role in the biological pump in the Beaufort Sea (Watanabe et al. 2014). The prevalent mesoscale eddies in the Canada Basin, with diameters around $10 \mathrm{~km}$, are concentrated in the stratified halocline (Timmermans et al. 2008; Zhao et al. 2014). There is a higher density in the southern portion of the basin (Plueddemann et al. 1998; Zhao et al. 2016) where anticyclonic flow is the strongest (Armitage et al. 2017). The depth, size, and core properties of eddies suggest that there are multiple source regions and formation mechanisms (Zhao et al. 2014), to include eddies arising from baroclinic instabilities in the basin interior and in boundary currents, such as the inflow of Pacific Water into the Arctic basin via the Alaskan Coastal Current (Manley and Hunkins 1985) or the Beaufort shelfbreak jet (Plueddemann et al. 1998; Pickart et al. 2013; Spall et al. 2008; Watanabe and Hasumi 2009), and mixed layer instabilities at surface fronts (Brannigan et al. 2017). Examining the distribution of eddy kinetic energy (EKE) provides a first step toward determining the relative contributions of those different instabilities to the mesoscale activity in the Arctic. In the open ocean, surface EKE has been estimated for decades based on satellite observations of SSH (e.g., Le Traon 1991). In the Arctic, ice cover has thus far prevented us to estimate surface EKE, and the recent SSH dataset developed by Armitage et al. (2016) remains at too low spatial $(\sim 25 \mathrm{~km})$ and temporal (monthly) resolution to resolve the mesoscale features in the region.

In this paper we use a high-resolution, eddy-resolving Arctic model to investigate the total KE and EKE fields in the Canada Basin, and their links with the dynamics of the Beaufort Gyre in a period of strong spinup. The remainder of this paper is structured as follows. Section 2 briefly presents the numerical model and simulation analyzed in this study. In section 3 , we provide a $3 \mathrm{D}$ description of the gyre and its temporal variations, and compare the model outputs to available observations. A detailed description of the temporal and spatial variations of the levels of total and eddy kinetic energy is given in section 4 , followed by a discussion of the mechanisms at play to explain their variations in section 5. Conclusions are given in section 6 .

\section{Methods}

In this study we make use of the regional Arctic-North Atlantic high-resolution model configuration named CREG12 (Canadian Regional; Dupont et al. 2015). A 5-day mean of model sea surface salinity (SSS) of the Arctic portion of the domain is shown in Fig. 1. CREG12 is a seamless regional extraction (i.e., the "north-fold" discontinuity of the global grid is removed) of the ORCA12 configuration developed jointly by the Drakkar consortium and Mercator-Océan (Barnier et al. 2006; Tréguier et al. 2014), encompassing the Arctic and parts of the North Atlantic down to $27^{\circ} \mathrm{N}$. It is based on the NEMO 3.6 (Madec 2016) and LIM 3.5 (Rousset et al. 2015) numerical models for the ocean and sea ice components, respectively. The configuration has a high vertical (75 levels) and horizontal $(3-4 \mathrm{~km})$ resolution in the Arctic Ocean, meaning that baroclinic eddies are resolved everywhere in the Arctic except on the shallow shelves (Dupont et al. 2015). Parameterizations include a Laplacian mixing of temperature and salinity along isopycnals, a horizontal biharmonic viscosity, and a 


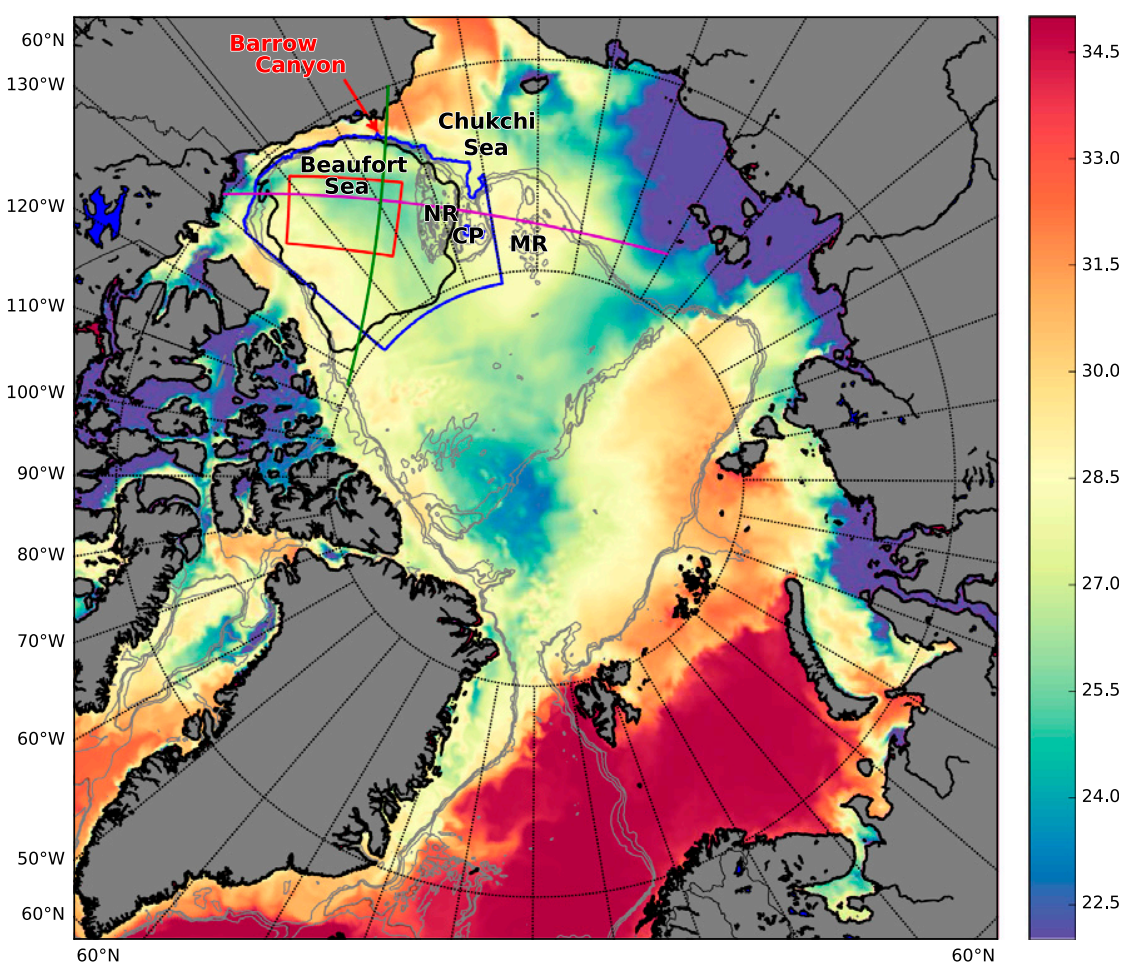

FIG. 1. Map of modeled sea surface salinity (SSS; psu) from the 5-day average centered on 3 Aug 2007. The corresponding gyre area defined as the largest closed sea surface height contour is shown in black. Key locations and regions used for computations are also shown: green (section A) and magenta (section B) lines indicate locations of cross sections through the center of the $1990-2014$ mean gyre at $74.74^{\circ} \mathrm{N}, 209.38^{\circ} \mathrm{E}$. Also shown are the BG box (blue box), a region defined as $70.5^{\circ}-80.5^{\circ} \mathrm{N}, 190^{\circ}-230^{\circ} \mathrm{E}$, and limited by the $300-\mathrm{m}$ bathymetry contour, and the central gyre (red box). Bathymetry contours are shown at 500,1000, and $1500 \mathrm{~m}$. The Beaufort Sea and Chukchi Sea are labeled, as are the Northwind Ridge (NR), Chukchi Plateau (CP), Mendeleev Ridge (MR), and Barrow Canyon.

turbulence closure scheme (TKE) for vertical mixing. The representation of tidal mixing effects is included in the new comprehensive parameterization of mixing by breaking internal tides and lee waves (de Lavergne et al. 2019).

Initial conditions are taken from the World Ocean Atlas 2009 climatology for temperature and salinity while the ocean is at rest. The initial sea ice thickness and concentration are taken from a long ORCA12 simulation performed by the Drakkar group. Along the lateral open boundaries, monthly climatological conditions (comprising 3D velocities, temperature and salinity, and sea ice thickness and concentration) are taken from the same ORCA12 simulation. In particular, the transport of volume, heat and freshwater through the Bering Strait are comparable to the observational estimates from Woodgate et al. (2015). Regarding the atmospheric forcing, we use the latest version of the Drakkar Forcing Set (DFS 5.2), which is an updated version of the forcing set described in Brodeau et al. (2010). Inputs from the river and ice sheet runoff are based on the Dai and Trenberth (2002) climatological dataset, which has been recently corrected to include the large and increasing contribution from Greenland (Hu et al. 2019).

The simulation covers the period 1979-2014, and we only analyze the following the period of 1990-2014, in order to allow for the adjustment of the ocean and sea ice conditions. All analysis is carried out on 5-day mean model outputs unless otherwise stated.

\section{Variability of the Beaufort Gyre}

We first evaluate the capacity of the model simulation to reproduce the spatiotemporal variability of the Beaufort Gyre as captured by available observational datasets. We make use of the altimetry-derived Dynamic Ocean Topography (DOT) dataset produced by Armitage et al. (2016, 2017), spanning 2003-14 with monthly temporal resolution and $0.75^{\circ} \times$ $0.25^{\circ}$ resolution in longitude and latitude, respectively. Following the method of Regan et al. (2019), 
we define the gyre in both the observations and the model output as follows, noting that model $\mathrm{SSH}$ is equivalent to observed DOT, albeit referenced to a different constant level. First, the maximum SSH within the box defined by $140^{\circ}-280^{\circ} \mathrm{E}, 68^{\circ}-81.5^{\circ} \mathrm{N}$ is deemed the gyre center. When the gyre is present, its $\mathrm{SSH}$ at the center exceeds that of individual eddies, so this method identifies the center of the gyre rather than an individual anticyclonic eddy (verified by visual inspection). Then the gyre area in the model is defined as the largest closed SSH contour around this maximum.

Based on this detection algorithm of the gyre, we find that the model successfully reproduces both the location of the Beaufort Gyre and its shift over 2003-14 (Figs. 2a,b). The annual-mean gyre extent varies between the deep basin with a western limit over the Northwind Ridge in 2003, to a bathymetry-bounded large gyre reaching the Mendeleev Ridge to the west and the continental slope north of the Canadian Arctic Archipelago to the east in 2014. The northward extent also generally varies in line with DOT observations. Quantitatively, some differences between the model and altimetry data do exist. Some are expected due to the differing resolutions of the two products; for example, more spatial variability might be expected in the model which is at a higher resolution. The increase of the gyre area and the shift of its center toward the northwest is also less linear in the model than in the observations, with the gyre area in the model being, for instance, roughly as large in 2005 as in 2012 (Fig. 2b). One should note that the maps shown Figs. $2 \mathrm{a}$ and $2 \mathrm{~b}$ are based on the detection of the gyre from annual-mean SSH, and thus the variations captured here slightly differ from the variability visible in Figs. $2 \mathrm{c}$ and $2 \mathrm{~d}$, which are based on monthly mean SSH fields. Nonetheless, the seasonal and interannual variability of the gyre area is well represented, with a correlation coefficient of 0.64 between the two time series after removing the linear trend (Fig. 2d). The mismatch in gyre area between the simulation and the observations in 2007 and 2008 is partly due to the $81.5^{\circ} \mathrm{N}$ northern limit of the satellite data before 2011.

The model also accurately simulates the maximum SSH variability when compared to the DOT variability from observations (Fig. 2c), with a correlation coefficient of 0.63 after detrending. This parameter was found to be a good proxy for the intensity of the gyre (Regan et al. 2019), and thus also reflects the variations of the freshwater content stored within the gyre (e.g., Proshutinsky et al. 2009). Indeed, when compared against the freshwater content estimated from summertime CTD and mooring data from the Beaufort Gyre Exploration Project (BGEP; Proshutinsky et al. 2020) averaged over a box bounded by $190^{\circ}-230^{\circ} \mathrm{E}, 70.5^{\circ}-$ $80.5^{\circ} \mathrm{N}$ (excluding the regions shallower than $300 \mathrm{~m}$ ), hereafter termed the "BG box," the documented increase in freshwater content occurring after 2007 is also captured well (Fig. 2e). A good representation of the integrated freshwater content suggests that the model is able to accurately represent the variations of both the salinity in the halocline and the depth of the isohalines (see also Figs. 3e-h).

Both the time series of the freshwater content and the maximum SSH (and thus the gyre intensity) suggest that a regime shift occurs in 2007-08, with a spinup phase occurring from 2003 to 2007, and a stabilization after 2008 , consistent with the modeling results of J. Zhang et al. (2016). In the following, we will contrast these two periods (referred to as "spinup" for 2003-07 and "postspinup" for 2008-14) when examining the energetics of the gyre, and compare them to the long term average (1990-2014). The variability of the gyre is partly driven by the surface forcing (Fig. 2g; Meneghello et al. 2017; Regan et al. 2019); the rapid shift occurring in 2007-08, which has been linked to short-lived anomalous surface forcing (e.g., Zhong et al. 2019b), is also discussed in section 5 .

While the observational datasets provide an accurate description of some aspects of the spatiotemporal variability of the Beaufort Gyre, models outputs are required to obtain a full $3 \mathrm{D}$ description of the gyre. To investigate its vertical structure, we use two sections that intersect at the 1990-2014 mean center of the gyre, referred to as sections A (south-north) and B (east-west), as shown in Fig. 1. The increase in SSH occurring from 1990 to 2014, associated with freshwater convergence within the gyre, is accompanied by a deepening of the halocline in the center of the gyre (Figs. 3a-d; corresponding bathymetry shown in Figs. 3i,j). Note that in the cold Arctic, isohalines and isopycnals are roughly equivalent. The mirroring of SSH and isohalines on time scales longer than a season is expected as the Beaufort Gyre dynamics can be examined considering the system as a fresh layer overlying a stationary Atlantic layer (e.g., Davis et al. 2014), that is thus governed by the dynamics of a 1.5layer reduced gravity model. The deepening in the gyre center was indeed seen in simple process models (e.g., Manucharyan and Spall 2016). However, the model mean salinity section here demonstrates a clear asymmetry across the gyre that was not captured in those idealized models (Figs. 3e,f) but is present in the MIMOC climatology (Schmidtko et al. (2013), plotted along sections A and B in Figs. $3 g$ and 3 h). Overall the model reproduces well the depth of the halocline and the steep salinity gradient across it, although the 

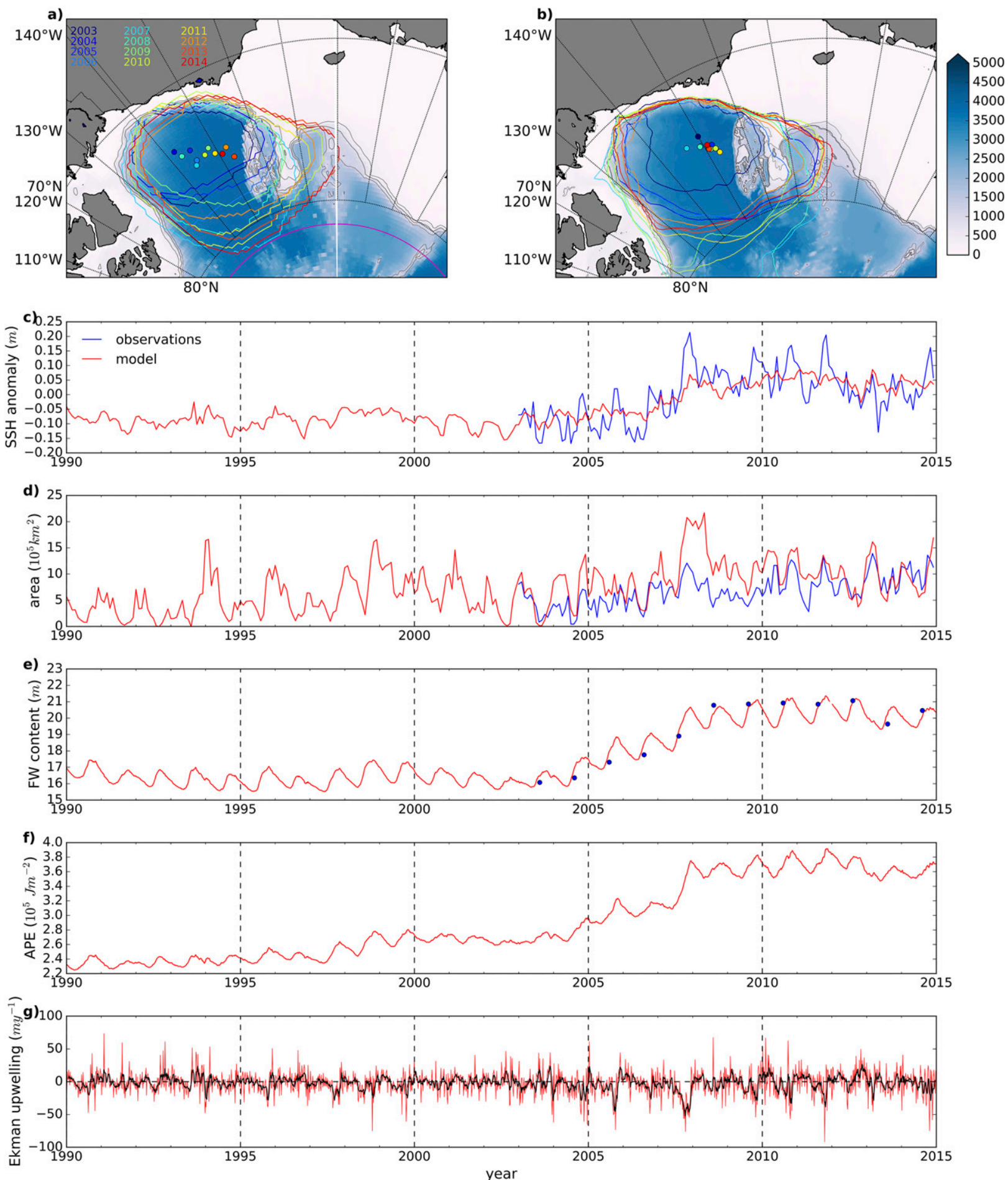

FIG. 2. Annual-mean gyre extent from 2003 to 2014 in (a) DOT observations from Armitage et al. (2016, 2017) and (b) the model, overlaid onto GEBCO bathymetry and model bathymetry, respectively. The center of the gyre in each year is also shown with a dot. (c) Anomaly from the 2003-14 mean of the monthly maximum height of the gyre SSH (red) and observed DOT (blue). (d) Monthly gyre area in the model (red) and observations (blue). (e) Average freshwater (FW) content relative to 34.8 psu in the BG box from the model (red) and the BGEP (blue dots). (f) Vertically integrated APE from the base of the halocline to the surface, based on the method by Polyakov et al. (2018). (g) Average Ekman pumping within the BG box (red, with 30-day running mean shown in black), estimated from the surface ocean stress from the model. 

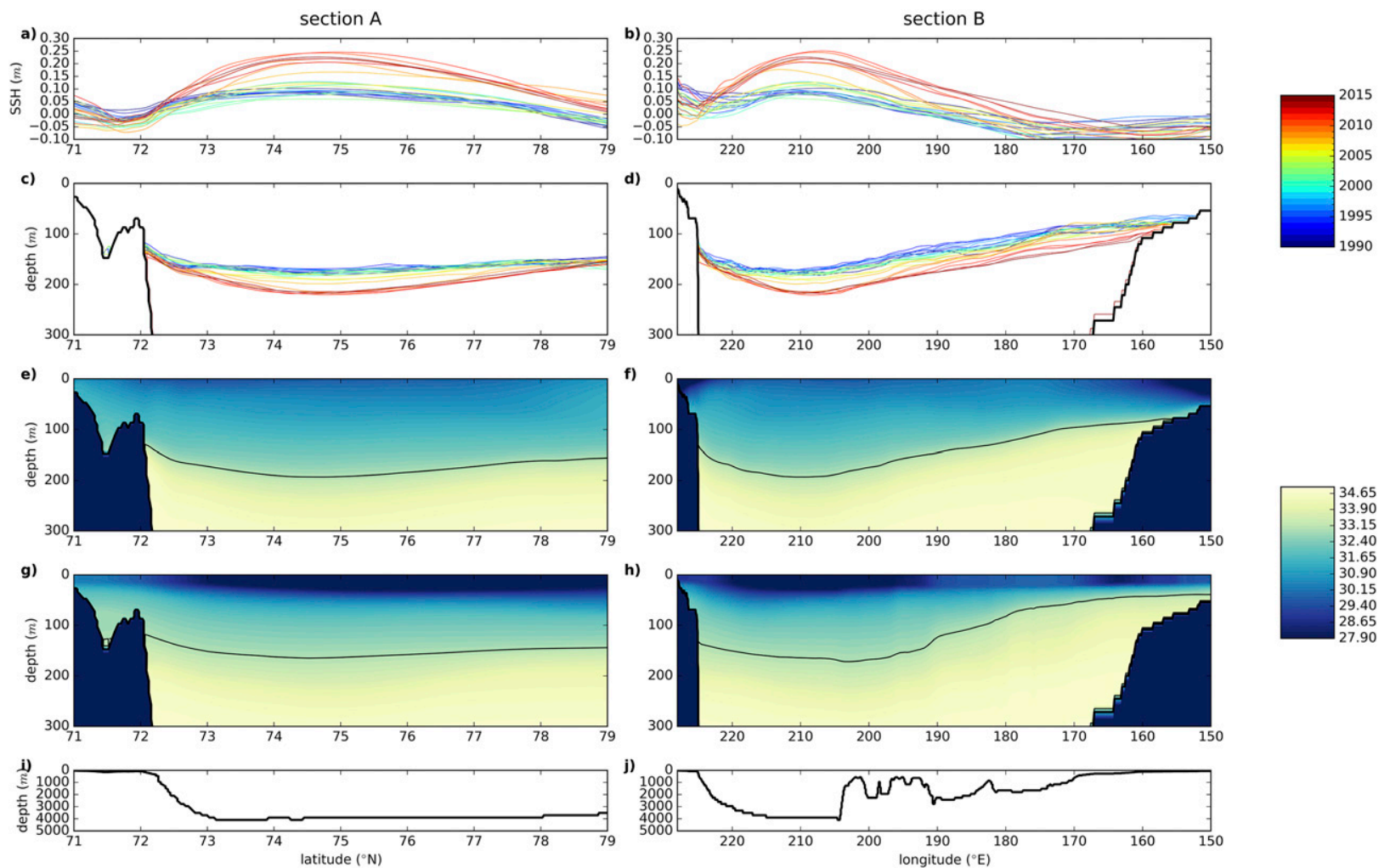

FIG. 3. Annual-mean SSH across (a) section A and (b) section B (see Fig. 1 for the locations). (c),(d) Annual-mean depth of the 33-psu isohaline across sections A and B, respectively. (e),(f) The 1990-2014 model climatology of salinity across sections A and B, with the 33-psu isohaline drawn in black. (g),(h) Salinity from the MIMOC climatology (Schmidtko et al. 2013), interpolated onto the model grid across the same sections, also with the 33-psu isohaline drawn in black. (i),(j) The bathymetry across sections A and B; the shallow bathymetry from $205^{\circ}$ to $190^{\circ} \mathrm{E}$ in section B is the Chukchi Plateau.

model is not as fresh at the surface as in observations. Note that this feature is most often poorly reproduced by state-of-the-art ocean-sea ice models (e.g., Lique et al. 2016; Wang et al. 2016). The deepest portion of the gyre occurs close to the southern and eastern bathymetry; on those sides of the gyre, isohalines are steep, while the northern and western portions have flatter isohalines. Over 1990-2014, the isohalines gradually deepen both at the center and over the portion of the gyre that is free to expand, whereas the side constrained by bathymetry varies less, as seen in the depression of the 33-psu isohaline (Figs. 3c,d). In conjunction with this, the center of the gyre moves farther away from the continental slope due to the northwest shift of the gyre as seen in Figs. 2a and $2 b$.

During the early 1990s, when surface forcing was often cyclonic (e.g., Fig. 2g; Proshutinsky et al. 2015), the 33 -psu isohaline is roughly flat all across the gyre (Figs. 3c,d). After 2000, as the center starts to shift toward the northwest, the depth of the 33-psu isohaline at the center of the gyre also increases. This deepening is accelerated between 2005 and 2010, and in particular during the year 2007 when there was an anomalously anticyclonic summertime Beaufort Sea high (Serreze and Barrett 2011) associated with anomalously strong downwelling during the year (Fig. 2g; Meneghello et al. $2018 b$ ). Thus, as a result of the gyre spinup and increased freshwater content within the gyre, the 33-psu isohaline through the gyre is depressed by $36 \mathrm{~m}$ when comparing the 1990-2007 and 2008-14 averages, deepening from 181 to $217 \mathrm{~m}$. A deepening of $15 \mathrm{~m}$ is seen between 2007 and 2008, and after 2010 the isohaline deepens west of $200^{\circ} \mathrm{E}$, which is concurrent with the expansion over the Chukchi Plateau. In the interior of the Beaufort Sea, Timmermans et al. (2014) observed a deepening of around 20 and $30 \mathrm{~m}$ of the 31- and 33-psu isohalines, respectively, between 2007 and 2008, which is similar to the rapid deepening in the center that we find here. The deepening of the isohalines is also consistent with the observed deepening of $\sim 30 \mathrm{~m}$ of the nutricline and chlorophyll maximum in the interior of the Canada Basin over the period 2003-09 reported by McLaughlin and Carmack (2010). One should remember, however, that the changes in isohaline depth are not solely a response 
to the dynamical wind forcing and might also reflect changes in water masses found in the halocline. For instance, using oxygen, temperature, and salinity measurements, Shimada et al. (2005) suggest that depressions in isohalines between 32.5 and 33.5 psu observed during summer 2002 and 2003 along $150^{\circ} \mathrm{W}$ could be attributed to a shift in the respective contributions of summer and winter Pacific Water inflow. This contribution is also likely to be affected by interannual changes to pathways and advection (Zhong et al. 2019a).

In summary, the model reproduces well the observed properties of the Beaufort Gyre and their spatial and temporal variability. The 3D description of the gyre obtained from the model suggests large changes of the depth and slope of the different isopycnals as the gyre spins up and stabilizes over time, suggesting potential implications for the development of baroclinic instability. In the following, we explore the response of the levels of total and eddy kinetic energy to the changes of the large-scale gyre circulation.

\section{Energetics of the Canada Basin}

\section{a. Computation of the total and eddy kinetic energy}

We start by defining the different metrics we use to examine the energetics in the Canada Basin, and explain how their calculations are performed. First, we compute the total kinetic energy $\mathrm{KE}$ as $\mathrm{KE}=0.5\left(u^{2}+v^{2}\right)$. We use the 5-day mean velocities $(u, v)$ for the computation. The velocities can be further decomposed into a time-mean and an eddy part, $(u, v)=\left(\bar{u}+u^{\prime}, \bar{v}+v^{\prime}\right)$, from which we can decompose $\mathrm{KE}$ into a mean kinetic energy $\left[\mathrm{MKE}=0.5\left(\bar{u}^{2}+\bar{v}^{2}\right)\right]$ and an eddy kinetic energy $\left[\mathrm{EKE}=0.5\left(u^{\prime 2}+v^{\prime 2}\right)\right]$ component. Here we follow Rieck et al. (2018) and use annual means to compute $\bar{u}$ and $\bar{v}$ as opposed to the long-term mean that is often considered (e.g., Hogg et al. 2015). This allows us to account for interannual variations of the mean currents and in particular for the effects of the gyre spinup that occurs over the period considered (Fig. 2). One should remember, however, that, while mesoscale eddies are expected to account for most of the EKE (Wunsch 2002), our EKE fields also account for short term variations of the large scale circulation as well as meanders and shifts of the current core and waves. In particular, we know that there is also some variability in the Beaufort Gyre circulation on seasonal time scales, but these variations remains small compared to the variations occurring on interannual-to-decadal time scales (e.g., Regan et al. 2019), and the EKE estimated using $\bar{u}$ and $\bar{v}$ computed as 3 - and 12-month running means gives qualitatively the same results as those presented in the following. An additional Reynolds stress term arises from the correlations between the mean and the fluctuation of each velocity component as our mean is constructed of annual means as opposed to the long-term mean; this term is an order of magnitude smaller than the MKE and EKE terms and is therefore neglected.

\section{b. Horizontal maps}

To quantify the spatial variability of the gyre energetics, we first examine maps of the long term means of $\mathrm{KE}, \mathrm{MKE}$, and EKE, both at the surface and in the halocline at $147 \mathrm{~m}$ (Figs. $4 \mathrm{a}-\mathrm{c}$ and $5 \mathrm{a}-\mathrm{c}$ ). The three fields are highly variable but there are a lot of similarities between them, both at the surface and in the halocline. Interestingly, the partition of KE into a mean and an eddy part reveals that the two are of the same order of magnitude both along the continental slope and in portions of the interior. This is at odds with what is observed in most of the open ocean at the surface, where EKE is thought to be one to two orders of magnitude more energetic than the MKE (e.g., Wunsch 2002), and is likely due to the small beta effect associated with the nonzonal mean flow (Spall 2000). The contrast is even more striking within the halocline at $147 \mathrm{~m}$, where MKE in the interior of the basin toward the northwest portion of the gyre exceeds the contribution to KE from EKE.

The most energetic part of the region appears as high $\mathrm{KE}$ along the continental slope in the southern Canada Basin (between $200^{\circ}$ and $230^{\circ} \mathrm{E}$ ) both at the surface and in the halocline (Figs. 4a and 5a). The values of KE there are an order of magnitude higher than in the basin interior in the 1990-2014 mean. This is also a region of elevated MKE and EKE compared to the interior, where the maximum EKE in the interior is just $7 \%$ of the maximum EKE on the slope at both the surface and $147 \mathrm{~m}$. Large surface MKE at this location is consistent with the highest geostrophic velocities observed by Armitage et al. (2017). The strongest mean currents are where most mesoscale eddies form (e.g., Manucharyan and Isachsen 2019), which here is reflected in the high levels of EKE found along the continental slope that regularly exceed $1 \times 10^{-2} \mathrm{~m}^{2} \mathrm{~s}^{-2}$, and reach up to $4 \times$ $10^{-2} \mathrm{~m}^{2} \mathrm{~s}^{-2}$ in isolated locations. This maximum in EKE in the boundary current corresponds to the largest lateral shear. Although high, the levels of EKE found there remain lower than in the energetic regions commonly found in the open ocean, for example the midlatitude western boundary currents and equatorial regions where EKE exceeds $5 \times 10^{-2} \mathrm{~m}^{2} \mathrm{~s}^{-2}$ over large areas (Rieck et al. 2015) and the Gulf Stream region where EKE can approach $2 \times 10^{-1} \mathrm{~m}^{2} \mathrm{~s}^{-2}$ in its most energetic part (Zhai et al. 2008). Nonetheless, the EKE along the continental slope in the Canada Basin is generally of a 

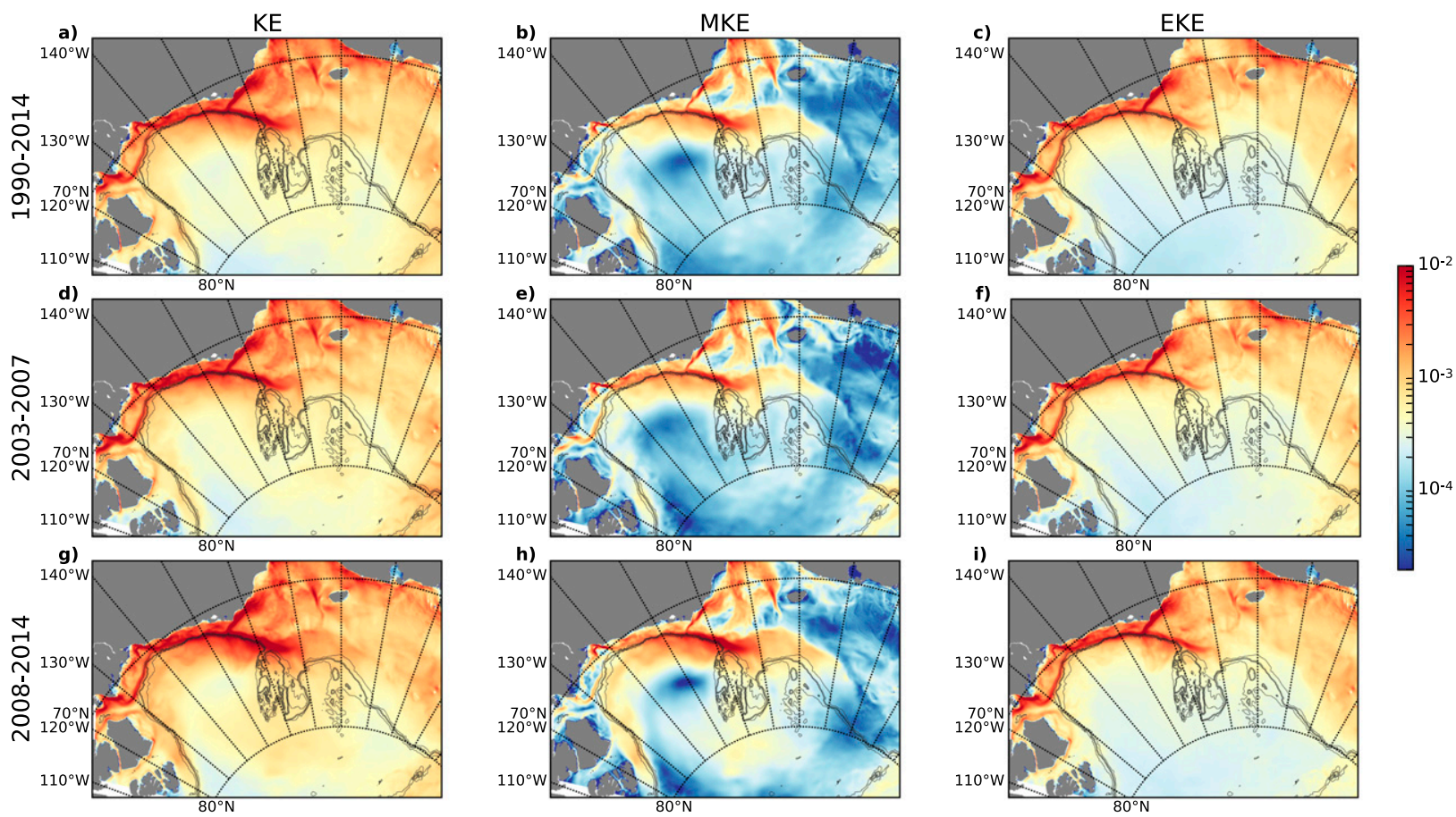

FIG. 4. Maps of (left) total KE, (center) MKE, and (right) EKE at the surface ( $\mathrm{m}^{2} \mathrm{~s}^{-2}$ ). Shown are the (a)-(c) 1990-2014 average, (d)-(f) 2003-07 (spinup) average, and the (g)-(i) 2008-14 (post-spinup) average. Bathymetry contours are shown at 500, 1000, and 1500 m in gray.

similar magnitude to that of the modeled EKE found by Trodahl and Isachsen (2018) in the Labrador and Nordic seas, though here the EKE is concentrated to a very narrow band while Trodahl and Isachsen (2018) find more widespread bands around shallow bathymetry and in the deep basin. The narrow band arises from a combination of coherent eddies generated from the boundary current or from the Barrow Canyon inflow that then follow the continental slope (Spall et al. 2008; von Appen and Pickart 2012) and boundary currents that can vary in both magnitude and direction on subannual time scales (e.g., Pickart 2004; Spall et al. 2018). An illustration of this is the temporary reversal of the eastward Beaufort shelfbreak jet observed in November 2002 by Pickart et al. (2013). Similarly, the inflow through Barrow Canyon also reverses subannually in the model (not shown), and the expanded gyre toward the latter part of the time period also reaches this region in winter (Regan et al. 2019). These variations are not accounted for in the annual-mean currents and therefore have an imprint on EKE.

Away from the continental slope, the partitioning of $\mathrm{KE}$ into EKE and MKE reveals different spatial distributions (Figs. $4 \mathrm{a}-\mathrm{c}$ and $5 \mathrm{a}-\mathrm{c}$ ). The mean EKE is qualitatively similar to the mean KE at both the surface and at $147 \mathrm{~m}$ across the Canada Basin, while the spatial distribution of MKE is more variable, with a clear imprint of the gyre within the basin interior. This is particularly visible on the northward extension of the gyre (north of $75^{\circ} \mathrm{N}$ ), where the gyre is not constrained by bathymetry and can move more freely (Regan et al. 2019). At 147 m, the northward extension of the gyre also has a signature on the EKE pattern, though the EKE remains low over the Chukchi Plateau.

While the basin interior is less energetic than the slope, eddies have been observed there previously (e.g., Newton et al. 1974; Timmermans et al. 2008; Zhao et al. 2016). Manley and Hunkins (1985) investigated the interior gyre $\mathrm{KE}$ (at approximately $75^{\circ} \mathrm{N}, 150^{\circ} \mathrm{W}$ ) using daily under-ice profiles over 1975-76, and found that the EKE made up over $98 \%$ of the total KE (with $37 \%$ of the EKE below $30 \mathrm{~m}$ attributable to individual eddies). This is at odds with our model results suggesting that MKE and EKE are of a similar order of magnitude in the interior, the average MKE and EKE as a percentage of $\mathrm{KE}$ in the central gyre (Fig. 1, red box) being $30 \%$ and $70 \%$ at the surface and $47 \%$ and $53 \%$ at $147 \mathrm{~m}$, respectively. This different partitioning could likely be attributed to the difficulty of defining a mean flow in regions with very weak mean currents contrasting with the passage of several highly energetic eddies.

Comparison of the spinup (2003-07) and post-spinup (2008-14) periods demonstrates a clear shift in energetics (Figs. $4 \mathrm{~d}-\mathrm{i}$ and $5 \mathrm{~d}-\mathrm{i}$ ). Indeed, the total KE significantly increases across the gyre during the latter period compared to the spinup phase, visible both at the 

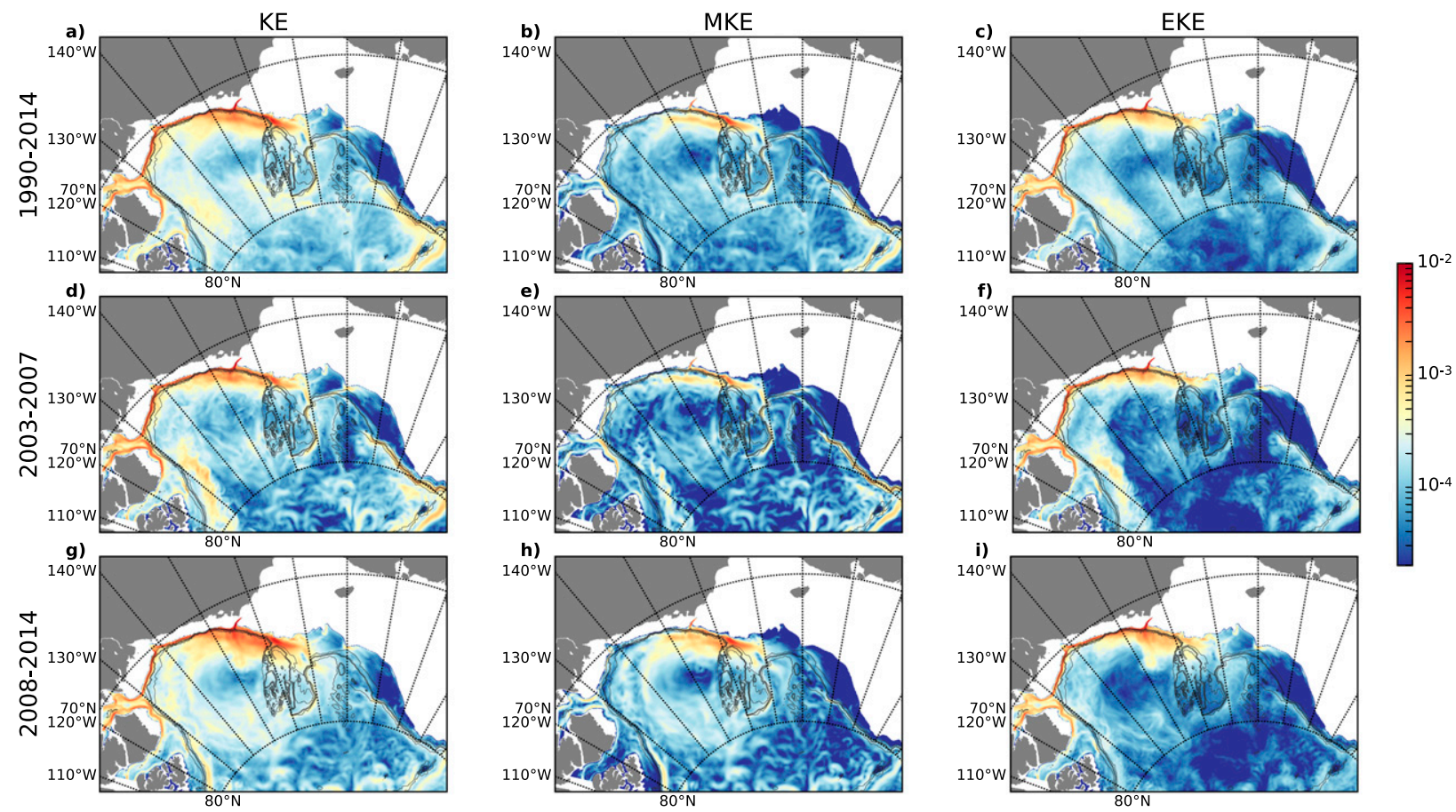

FIG. 5. Maps of (left) total KE, (center) MKE, and (right) EKE $\left(\mathrm{m}^{2} \mathrm{~s}^{-2}\right)$ at $147 \mathrm{~m}$, in the halocline. Shown are the (a)-(c) 1990-2014 average, (d)-(f) 2003-07 (spinup) average, and the (g)-(i) 2008-14 (post-spinup) average. Bathymetry contours are shown at 500, 1000, and $1500 \mathrm{~m}$ in gray.

surface and in the halocline. Given that the main dynamical equilibrium of the gyre determined from simple process models is thought to be a balance between the Ekman pumping and eddy flux (Davis et al. 2014; Doddridge et al. 2019), one would expect that the spinup of the gyre would result in an increase of the EKE [although some delay of the response could be expected arising from the so-called eddy memory mode described by Manucharyan et al. (2017)]. Our simulation shows that this is not the case. Looking at the partitioning between MKE and EKE reveals that the raise in total KE is predominantly due to a raise in MKE, which increases by up to $2 \times 10^{-4} \mathrm{~m}^{2} \mathrm{~s}^{-2}$ both at the surface and at $147 \mathrm{~m}$ in the interior between the two periods. At $147 \mathrm{~m}$, this results in MKE contributing over double that of EKE across the gyre interior. Along the continental slope, where Armitage et al. (2017) reported the strongest increase in geostrophic currents in 2007-10 compared to 2003-07, the MKE increases even more, with an increase exceeding $2 \times 10^{-3} \mathrm{~m}^{2} \mathrm{~s}^{-2}$ at the surface and $1 \times$ $10^{-3} \mathrm{~m}^{2} \mathrm{~s}^{-2}$ at $147 \mathrm{~m}$ around $200^{\circ} \mathrm{E}$. The increase is particularly visible along the energetic southwestern portion of the basin, with a widening band at the surface appearing in the post-spinup period, extending from where the gyre reaches the continental slope by the Chukchi Sea (between $200^{\circ}$ and $205^{\circ} \mathrm{E}$ ) and into the gyre interior, particularly north of Barrow Canyon. In contrast, the EKE increases much less between the two periods, and the spatial pattern remains broadly similar.

\section{c. Vertical sections across the gyre}

To better understand the changes visible on the energy maps, we examine the vertical distribution of KE, MKE, and EKE across the gyre for the same three periods (Fig. 6), making use of section B (see Fig. 1 for the location of the section).

On the long-term mean, the total KE is intensified across the surface of the gyre, down to $\sim 30 \mathrm{~m}$, which corresponds broadly to the base of the mixed layer (Fig. 6a). Below this, extending down to around $200 \mathrm{~m}$, there is an additional halocline signature. This is in line with the vertical structure of KE observed by Manley and Hunkins (1985): a surface peak in the top 0-30 m (due to energy in the mixed layer from ice motion and wind), followed by a subsurface KE peak with maxima at $120 \mathrm{~m}$ and extending from $30 \mathrm{~m}$ to the lower limit of the dataset $(200 \mathrm{~m})$. In the halocline, localized enhancements of KE reach up to $4 \times 10^{-4} \mathrm{~m}^{2} \mathrm{~s}^{-2}$, with values generally exceeding $1 \times 10^{-4} \mathrm{~m}^{2} \mathrm{~s}^{-2}$. Looking at the partitioning between MKE and EKE reveals that the structure of KE results from both contributions, depending on the region considered (Figs. 6b,c). In the interior of the gyre, away from the continental slope and below the mixed layer, MKE exhibits coherent values 

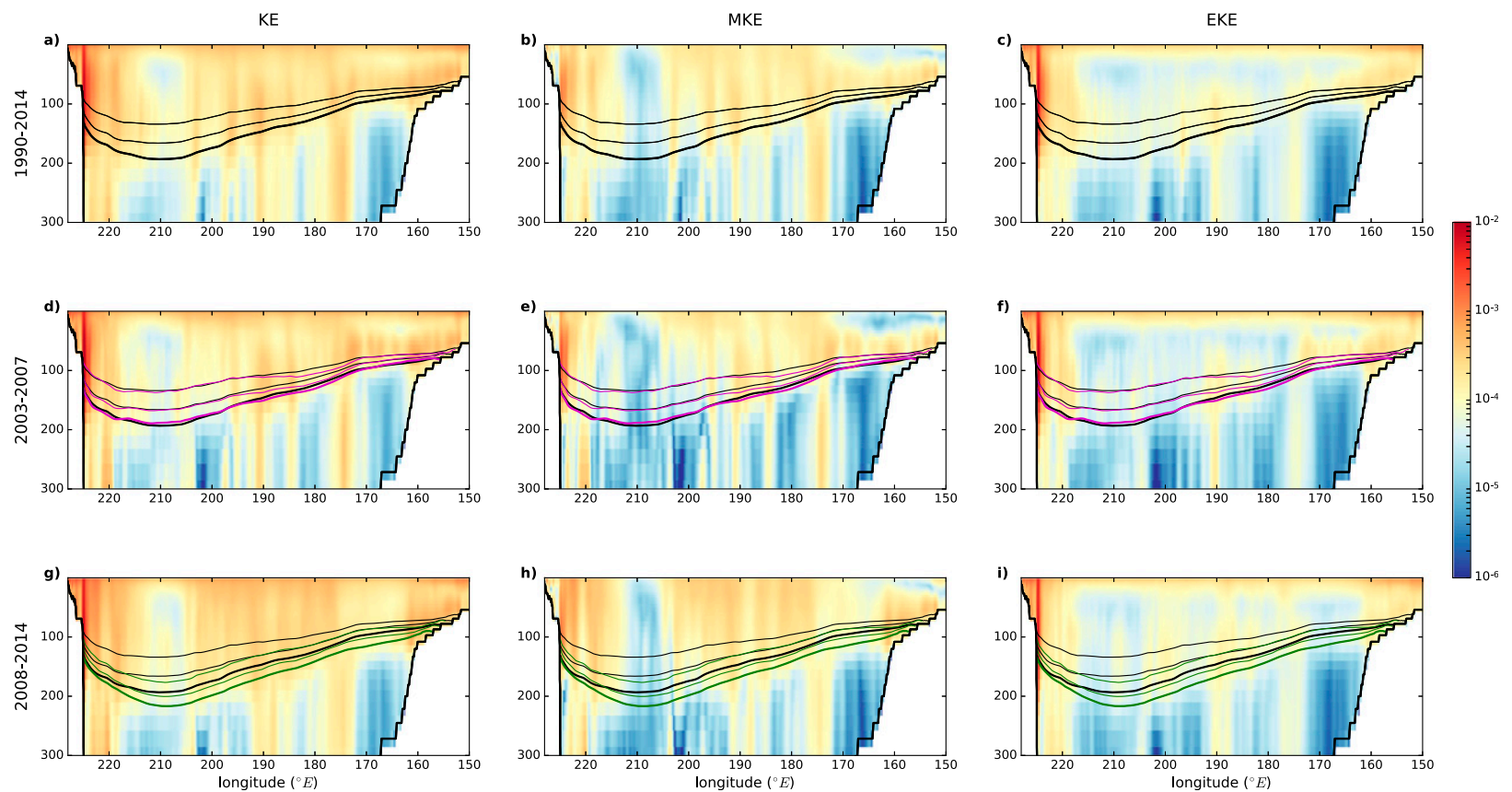

FIG. 6. Vertical sections of annual-mean (left) KE, (center) MKE, and (right) EKE $\left(\mathrm{m}^{2} \mathrm{~s}^{-2}\right.$ ) along section B (see Fig. 1). Shown are the (a)-(c) 1990-2014 average, (d)-(f) 2003-07 (spinup) average, and the (g)-(i) 2008-14 (post-spinup) average. Black lines indicate the 19902014 mean positions of the 32-, 32.5-, and 33-psu isohalines, with 33 psu in bold. Magenta and green lines indicate the same isohalines but for the 2003-07 and 2008-14 averages, respectively. Note that the Chukchi Plateau is located between $205^{\circ}$ and $190^{\circ} \mathrm{E}$ here.

around $1 \times 10^{-4} \mathrm{~m}^{2} \mathrm{~s}^{-2}$ throughout the halocline excepting the gyre center and accounts for most of the KE, while the surface intensification of $\mathrm{KE}$ across the section reflects high levels of EKE. Along the continental slope and over the Chukchi Plateau (Figs. 6a-c, longitudes $230^{\circ}-220^{\circ} \mathrm{E}$ and $205^{\circ}-190^{\circ} \mathrm{E}$, respectively), both MKE and EKE contribute significantly to KE, although the EKE is larger than the MKE.

A striking feature of the vertical section of EKE is the subsurface intensification, with, for example, values at $114 \mathrm{~m}$, in the subsurface peak, being over $85 \%$ of the average EKE in the top $10 \mathrm{~m}$ at $190^{\circ} \mathrm{E}$. This is again in sharp contrast with what is usually reported from observations or models in the open ocean, where EKE tends to decrease significantly with depth [e.g., in the Gulf Stream (Richardson 1983), the South China Sea (Z. Zhang et al. 2016), and the southeast Pacific (Balwada et al. 2016)]. A similar behavior was found in the Arctic modeling study of Maslowski et al. (2008) who reported that EKE can reach $1 \times 10^{-3} \mathrm{~m}^{2} \mathrm{~s}^{-2}$ at the surface and around $300 \mathrm{~m}$ offshore of the continental slope.

The general spatial and depth-dependent distributions of the energetics are enhanced when the gyre is spun up (Figs. $4 \mathrm{~g}-\mathrm{i}, 5 \mathrm{~g}-\mathrm{i}$, and $6 \mathrm{~g}-\mathrm{i}$ ). The spinup phase is comparable to the 1990-2014 mean (Figs. 6d-f), and the lower halocline EKE is actually reduced during the spinup over $2003-07$ between $190^{\circ}$ and $215^{\circ} \mathrm{E}$ (Figs. 6c,f). However, in the post-spinup phase (200814), all quantities increase as the isohalines in the gyre deepen from the 1990-2014 mean (Figs. 6g-i; also shown in Fig. 3). As already suggested by the maps, the MKE response is over double that of EKE in the interior gyre and more widespread consistently below $30 \mathrm{~m}$, but the EKE response, while elevated at depth, is not increased greatly, despite the deepened isopycnals (Figs. 6c,i). Indeed, large reductions in EKE are visible on the continental slope (east of $218^{\circ} \mathrm{E}$ ) at depth by over $1 \times 10^{-3} \mathrm{~m}^{2} \mathrm{~s}^{-2}$. In contrast to EKE, the MKE increases all across the gyre, again accounting for most of the increase in KE. The vertical sections also reveal that the widening of the boundary current along the eastern side of the gyre is coherent from the surface to the base of the halocline (Fig. 6h).

\section{d. Temporal evolution}

The clear shift in energetics between the two periods raises the question of how the transition occurs. Figure 7 shows Hovmöller plots of KE, MKE, and EKE averaged spatially across both the BG box (a region encompassing the full gyre; see blue box in Fig. 1) and the central gyre region (representative of the gyre interior; see red box in Fig. 1). There is a clear elevated signal in all quantities down to around $200 \mathrm{~m}$, with this depth varying 

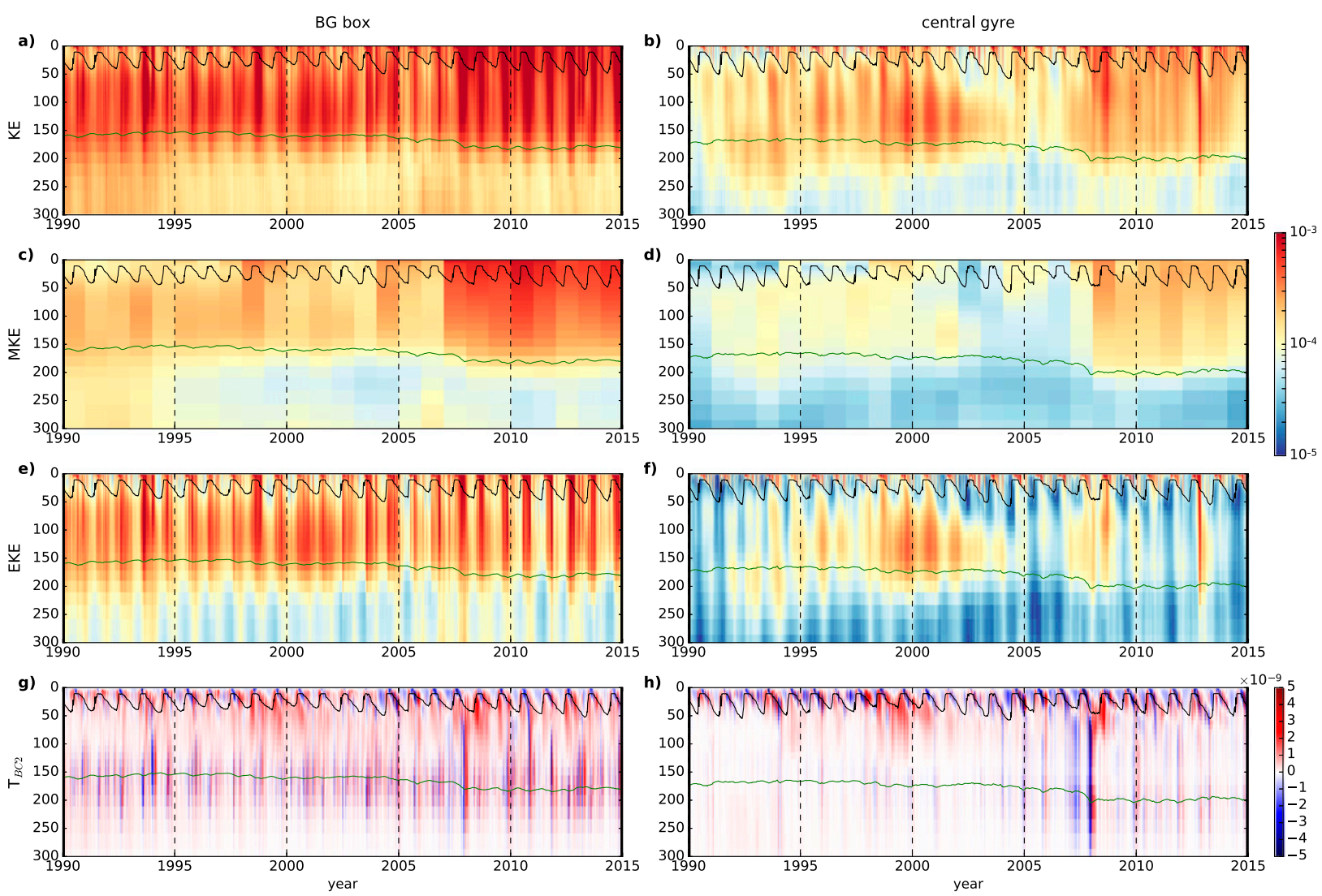

FIG. 7. Hovmöller diagrams of depth against time showing fields spatially averaged within the (left) BG box and (right) central gyre (see Fig. 1). Fields displayed are (a),(b) total KE, (c),(d) MKE, (e),(f) EKE (all in $\mathrm{m}^{2} \mathrm{~s}^{-2}$ ), and (g),(h) $T_{\mathrm{BC} 2}\left(\mathrm{~m}^{2} \mathrm{~s}^{-3}\right.$; positive $=$ conversion to EKE). The average mixed layer depth and depth of the 33-psu isohaline in each region are shown in black and green, respectively.

slightly both interannually and seasonally. This depth corresponds broadly with the lower limit of the gyre defined by the 33-psu isohaline (Fig. 3). Comparing the energy levels within the full gyre to the interior, the Hovmöller plots reveal that the temporal evolution of $\mathrm{KE}$ and its partitioning are similar in both the BG box and central gyre, although the energy is roughly an order of magnitude lower when only the gyre interior is considered.

A strong increase in the top $200 \mathrm{~m}$ of the MKE (and thus of the total KE) is visible after 2008, with a doubling above $80 \mathrm{~m}$ and the top $20 \mathrm{~m}$ being over 3 times higher on the 2008-14 average compared to the 1990-2007 average, in line with the transition identified from the time series of the freshwater content and gyre intensity (Fig. 2), although here the transition seems sharper. This transition is likely the result of the strong anomalous downwelling occurring in 2007-08 (Fig. 2g; Regan et al. 2019; Meneghello et al. 2018b) that may have served to help shift the gyre into a new equilibrium, with higher mean currents, but also higher levels of EKE in 2007-08 visible on Fig. $7 \mathrm{f}$ in the central gyre. Yet, after 2008, the
MKE remains high while the EKE appears to decrease again, resulting in the weak EKE signature in the spunup vertical section compared to the elevated MKE (Figs. 6h,i).

In the central gyre, there is also an increase in $\mathrm{KE}$ in 1998 (Fig. 7b), due to the beginning of the anticyclonic phase of the atmospheric circulation (e.g., Proshutinsky et al. 2015). It results in temporary gyre spinup, with the raised total KE predominantly due to an increase in EKE as opposed to MKE, in contrast to the 2007-08 rise. It is also accompanied by a small rise in SSH and freshwater content (Fig. 2), but the interannual rise is dwarfed by seasonal variability. In this situation, the gyre appears to fully readjust to the pre-spinup values without reaching a new equilibrium.

It is also interesting to examine the seasonal variations of EKE, which strongly affect the temporal evolution of KE. Notably, the surface signal identified in the EKE section is a highly energetic, summer-intensified signal that quickly disappears in the autumn and does not return until the spring. This is most likely due to a combination of friction of sea ice at the surface dissipating 
the energy (Ou and Gordon 1986) and also a lack of generation of surface baroclinic eddies in the winter due to the presence of sea ice, suggesting that an intensification of the surface EKE would likely not survive longer than the seasonal time scales. The surface intensification of the EKE appears more connected to subsurface EKE after 2007 in the BG box, likely due to the receding sea ice during that period reducing the dissipation of eddies at the surface in parts of the region. In contrast, the layer of enhanced EKE in the halocline intensifies and thickens over summer-autumn but remains year-round. The presence of some seasonality here is partly explained by the definition of EKE used, which encompasses the seasonal variations of the mean currents, and also the use of a fixed box for our average, both of which do not account for the seasonally expanding and contracting gyre. In the central gyre, the largest levels of EKE are found in 2012 and are related to a large individual eddy from Barrow Canyon entering the gyre during the August and remaining until the spring (not shown), that imprints strongly on the central gyre EKE and total KE (Figs. 7b,f). Timmermans et al. (2008) observed subsurface eddies such as this and suggested from current speed measurements that, assuming a straight path, they can have a lifetime of at least 6-18 months when advected into the interior of the basin.

In the next section we explore the mechanisms at play to generate the EKE in the context of the gyre spinup.

\section{Generation of eddy kinetic energy in the gyre}

\section{a. Computation of potential energy and energy transfer}

To better understand the variability in EKE in the gyre, we look at EKE generation via baroclinic instability, which idealized models suggest is the first-order response to Ekman pumping to stabilize the gyre (e.g., Manucharyan and Spall 2016; Davis et al. 2014; Doddridge et al. 2019). To do this, we compute the transfer of eddy potential energy (EPE) to eddy kinetic energy (EKE), which is associated with local baroclinic instability (e.g., Beckmann et al. 1994; Eden and Böning 2002; von Storch et al. 2012). This is the secondary stage of the Lorenz energy cycle, the first being mean potential energy (MPE) to EPE. The EPE $\rightarrow$ EKE transfer term can be written as a vertical buoyancy flux anomaly $T_{\mathrm{BC} 2}=\overline{w^{\prime} b^{\prime}}$ where $w$ is vertical velocity, $b=-g\left(\rho / \rho_{0}\right)$ is buoyancy, and $\rho_{0}=1027.5 \mathrm{~kg} \mathrm{~m}^{-3}$. As in the EKE computation, the prime denotes the anomaly from the annual means, meaning that the seasonal cycles of both the Ekman pumping and the buoyancy might also contribute significantly to $T_{\mathrm{BC} 2}$ without driving baroclinic instabilities. Overall, a positive value of $T_{\mathrm{BC} 2}$ indicates a transfer from EPE to EKE, meaning that lighter water masses are associated with upward motions, and denser water masses are associated with downward motions (e.g., von Storch et al. 2012). In this situation, the model isohalines flatten, releasing potential energy, and EKE is generated in the process. A negative value of $T_{\mathrm{BC} 2}$ indicates lighter water masses being associated with downward movements, such as a deepening of the isohalines in the gyre due to Ekman pumping. For comparison with this term, we also compute the MPE to EPE transfer term as $T_{\mathrm{BC} 1}=-\left(g / \rho_{0}\right)\left[(\partial z / \partial x) \overline{u^{\prime} \rho^{\prime}}+(\partial z / \partial y) \overline{v^{\prime} \rho^{\prime}}\right]$ (e.g., Beckmann et al. 1994). Negative values of both terms mean a transfer from EKE to the available potential energy (APE) reservoir, while positive values of both terms mean a transfer from the potential energy reservoir to EKE. Note that, in our model, we found that the generation of EKE through barotropic instability is an order of magnitude lower than that of baroclinic instability (not shown).

Given that the baroclinic instability results in an energy transfer between the potential and kinetic energy reservoirs, it is instructive to look briefly at the potential energy reservoir itself. This quantity is not well defined. It encompasses both available and background potential energy, of which only the former (APE) is readily available for exchange to kinetic energy (Winters et al. 1995). As such, attempting to rigorously estimate MPE, EPE, and APE is beyond the scope of the study. To step away from this complexity, we only look at the total APE, which has been suggested by Polyakov et al. (2018) to provide information on the stratification in the halocline and its stability. Following Polyakov et al. (2018), we estimate the vertically integrated total APE as $\mathrm{APE}=\int_{z=0}^{z_{1}} g\left(\rho-\rho_{\mathrm{ref}}\right) z d z$, where $g$ is gravitational acceleration, $z$ is depth, $z_{1}$ is the depth of the halocline base, and $\rho_{\text {ref }}$ is the potential density at the base of the halocline. As in Polyakov et al. (2018) and Bourgain and Gascard (2011), the halocline depth here is the depth below the mixed layer at which $[\alpha(d \theta / d z)] /[\beta(d S / d z)]=0.05$, where $\alpha$ and $\beta$ are the thermal expansion and haline contraction coefficients, respectively. Bourgain and Gascard (2011) note that this ratio can be used to identify a shift from the halocline to the thermocline; they found that a ratio of 0.05 resulted in the best fit for identifying the transition in individual pressure, temperature, and salinity profiles. The total APE averaged in the BG box here (Fig. 2f) has a magnitude similar to that found in 
observations from ships and ITP data within a similar box by Polyakov et al. (2018). They also found a monotonic increase in APE between 2005 and 2010 on their annual-mean computations, although our model results are around $1 \times 10^{5} \mathrm{~J} \mathrm{~m}^{-2}$ larger in the spun-up phase after 2008 than the APE of Polyakov et al. (2018). We note here that, as expected, the total APE variability closely follows that of freshwater content (Figs. 2e,f). The elevated APE after 2008, being nearly $30 \%$ larger in the spun-up phase than in the pre-spinup phase, suggests that the gyre halocline is deeper and more stable in the post-spinup phase than before, potentially limiting the ability to mix heat between the surface and the Atlantic Water below despite increased surface forcing due to sea ice decline (Davis et al. 2016) and likely affecting the intensity of the circulation in the Atlantic Water layer (Lique and Johnson 2015).

\section{b. Time evolution of energy transfer}

To analyze the transfer of energy between EPE and EKE due to baroclinic instability in the region, we first look at Hovmöller plots of $T_{\mathrm{BC} 2}$ averaged within the BG box and central gyre (Figs. 7g,h). Most of the energy transfer occurs within the top $200-300 \mathrm{~m}$ where the gyre resides. The magnitude of $T_{\mathrm{BC} 2}$ is higher when considering the BG box rather than just the central gyre due to the inclusion of the boundary current, which is known to generate eddies via baroclinic instability (e.g., Spall et al. 2008). This can also be seen in horizontal maps of $T_{\mathrm{BC} 2}$ at $147 \mathrm{~m}$ depth in 2007 and 2008 (Fig. 8). Just as for EKE (Figs. 7e,f), the vertical structure of $T_{\mathrm{BC} 2}$ displays bands of different behavior with depth, although on the temporal average, $T_{\mathrm{BC} 2}$ is positive below $15 \mathrm{~m}$, suggesting an overall transfer to EKE. In the mixed layer itself, the predominant behavior is a weakly negative $T_{\mathrm{BC} 2}$, while at the mixed layer base, there is a seasonal shift between strongly positive and negative $T_{\mathrm{BC} 2}$ as the mixed layer shoals and deepens. This seasonal cycle of $T_{\mathrm{BC} 2}$ is consistent with the seasonal cycle exhibited by APE (Fig. 2f), and is likely driven by seasonal inputs of freshwater from sea ice melt and freezing and terrestrial runoff and interactions with the surface forcing. Reduced negative $T_{\mathrm{BC} 2}$ in the mixed layer between 2001 and 2004 also corresponds to a period reduced seasonality of the APE (Fig. 2f).

Further down the water column, the transfer of energy is generally weaker, particularly in the central gyre, though there are still periods with elevated values (Figs. 7g,h). In the lower halocline there are short-lived episodes of both positive and negative $T_{\mathrm{BC} 2}$ which may be due to the shifting position of the halocline base and associated isohalines as the gyre expands and contracts seasonally. The layer between the surface and lower halocline, where EKE is reduced (Fig. 7f), has a band of positive $T_{\mathrm{BC} 2}$ in the $\mathrm{BG}$ box throughout the time period (which is also present in the central gyre but with a lower magnitude). Notably, in this layer in 1998-2002 and 2007-08 there is a strong positive $T_{\mathrm{BC} 2}$ signal in both the BG box and the central gyre, corresponding to years when the EKE is also elevated in the halocline in the central gyre (Fig. 7f). The former is preceded by a strong negative $T_{\mathrm{BC} 2}$ signal, suggesting conversion to potential energy that extends deep into the water column in the central gyre (Fig. 7h). The signatures of the elevated EKE extend deeper in the water column (down to the gyre base) than the positive $T_{\mathrm{BC} 2}$ (down to $100 \mathrm{~m}$ ), and appear with a time lag of the order of a few weeks, likely due to the growth time of the instabilities (G. Meneghello et al. 2019, unpublished manuscript).

The transition to higher total KE and MKE occurs abruptly over 2007-08 (Figs. 7a-d), unlike the gradual increase in freshwater content and APE during the 2000s (Figs. 2e,f). It coincides with the largest subsurface $T_{\mathrm{BC} 2}$ in the central gyre (Fig. $7 \mathrm{~h}$ ) during a year of anomalously strong downwelling (Fig. 2g; Meneghello et al. 2018b). Zooming into the transition, Figs. $8 \mathrm{a}, 8 \mathrm{~b}, 9 \mathrm{~b}$, and $9 \mathrm{e}$ show maps at $147 \mathrm{~m}$ and vertical sections across section $\mathrm{B}$ of $T_{\mathrm{BC} 2}$ for the 2007 and 2008 annual means. The $T_{\mathrm{BC} 1}$ term is also shown in Figs. 9c and $9 \mathrm{f}$ for comparison. The signature in 2007 is dominated by strong negative $T_{\mathrm{BC} 1}$ down to around $50 \mathrm{~m}$, and a gyre-wide negative $T_{\mathrm{BC} 2}$, which extends from around 50 to $300 \mathrm{~m}$ (Fig. 9b). There is an additional, weaker lower halocline signature in the eastern gyre in $T_{\mathrm{BC} 1}$. This strong negative signal of both $T_{\mathrm{BC} 1}$ and $T_{\mathrm{BC} 2}$ suggests an overall large transfer from EKE to the MPE reservoir. Figure $7 \mathrm{~h}$ suggests that in 2008, there is a subsequent strong positive $T_{\mathrm{BC} 2}$, but this is more localized, mainly along the continental slopes (Fig. 8b) and close to the surface (Fig. 9e), and it does not dominate the interior gyre at depth like the negative signal in 2007 (Figs. 9b,e). In general, the localized distribution of $T_{\mathrm{BC} 2}$ in 2008 is more typical of other years in the study period, though slightly enhanced (not shown). Thus, while the gyre usually experiences a net transfer to EKE via baroclinic instability, in 2007 there is instead a strong, gyre-wide transfer to MPE and EPE, the latter of which occurs down to the gyre base, and is reflected in the total APE (Fig. 2f).

A comparison of EKE, $T_{\mathrm{BC} 1}$, and $T_{\mathrm{BC} 2}$ over the transition shows that areas of steeper isohalines compared to the 1990-2014 mean isohalines are accompanied by high levels of both positive $T_{\mathrm{BC} 2}, T_{\mathrm{BC} 1}$, and EKE 


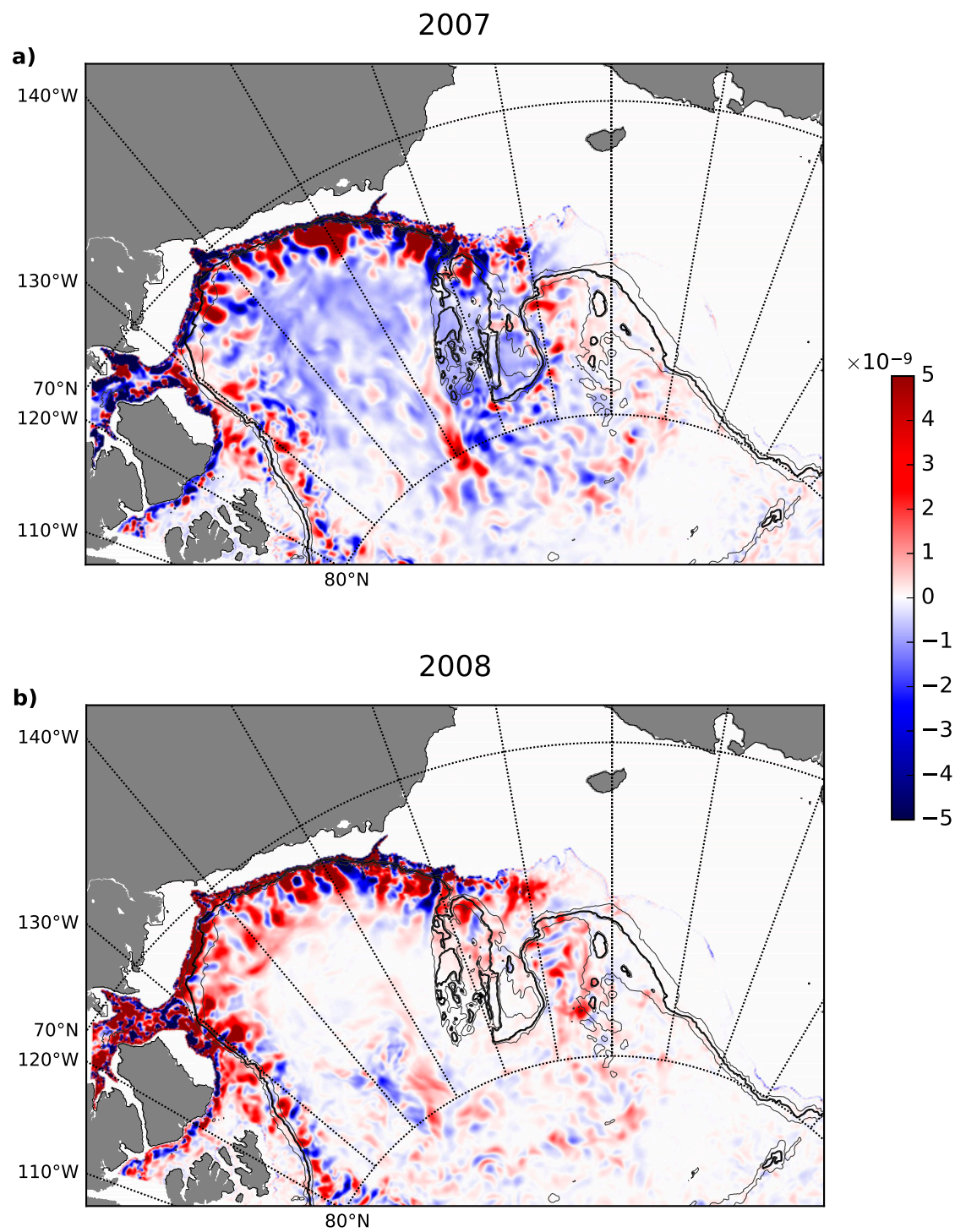

FIG. 8. Maps of annual-mean $T_{\mathrm{BC} 2}\left(\mathrm{~m}^{2} \mathrm{~s}^{-3}\right.$; positive = conversion to EKE), at $147-\mathrm{m}$ depth for (a) the 2007 average and (b) the 2008 average. Bathymetry contours are outlined at 500 , 1000 , and $1500 \mathrm{~m}$.

(e.g., between 50 and $150 \mathrm{~m}$ at $200^{\circ} \mathrm{E}$ in Figs. 9d-f). Therefore EKE is generated via baroclinic instability where isohalines steepen. However, this is not enhanced significantly (Figs. 9a,d) in response to the gyre-wide negative $T_{\mathrm{BC} 2}$. Thus, an anomalous year of Ekman pumping serves to change the mean state of the gyre, but EKE is only elevated temporarily (Fig. 7h). With the exception of Manucharyan and Spall (2016) and Manucharyan et al. (2017), idealized models have historically used a step change in surface forcing and analyzed the gyre response and its time scale. This differs from the scenario here, which is a short-lived change in surface forcing. It is clear from this analysis that such fluctuations of the magnitude of the forcing are an important consideration, affecting the gyre MKE and EKE on different time scales.

\section{c. Role of bathymetry and gyre asymmetry}

We have shown that, in contrast to what has been suggested from idealized process models, the spinup of the gyre is largely accompanied by an increase in MKE while the EKE does not increase significantly. We thus investigate how the interior of the gyre adjusts to its new state.

The continental slope, over which the gyre has expanded during the spinup phase (Fig. 2b), has recently been described as a feature that tends to impede the development of baroclinic instability (Manucharyan and Isachsen 2019). Starting from the Eady theory 

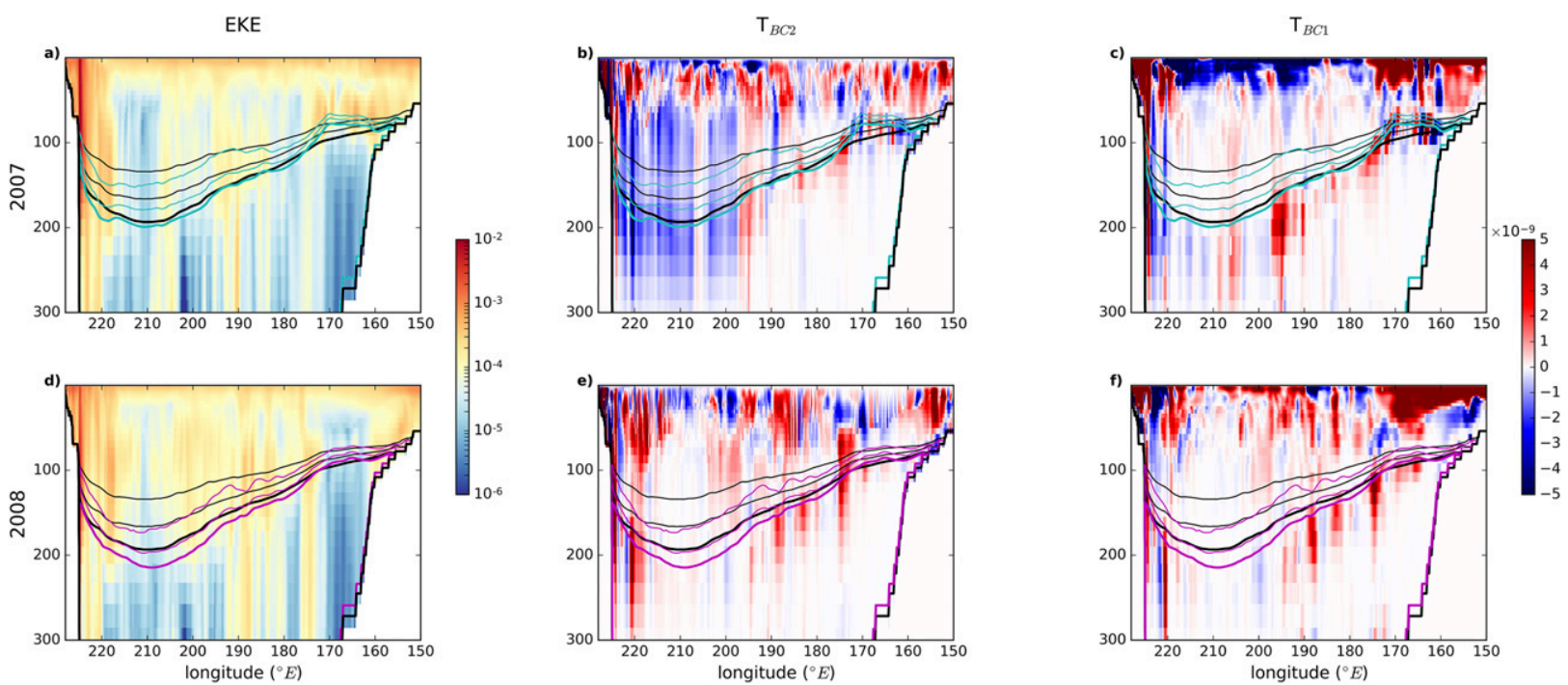

FIG. 9. Annual-mean vertical sections along section B (see Fig. 1) of (left) EKE $\left(\mathrm{m}^{2} \mathrm{~s}^{-2}\right.$ ) and (center) $T_{\mathrm{BC} 2}$ and (right) $T_{\mathrm{BC} 1}$ (both in $\mathrm{m}^{2} \mathrm{~s}^{-3}$; positive = conversion to EKE). Plots are shown for the (a)-(c) 2007 average and (d)-(f) 2008 average. Black lines indicate the 1990-2014 mean positions of the 32-, 32.5-, and 33-psu isohalines, with 33 psu in bold. The annual-mean isohalines at 32, 32.5 and 33 psu are shown in cyan (2007) and magenta (2008). Note that the Chukchi Plateau is located between $205^{\circ}$ and $190^{\circ} \mathrm{E}$ here.

(Eady 1949), a simple parameter $\delta=s_{b} / s$ (where $s$ is the isopycnal (isohaline) slope and $s_{b}$ is the slope of the bathymetry) can be defined and used to determine if the current over the slope is baroclinically stable or not. According to this simple formulation, the southern portion of the gyre lies within the $\delta>1$ regime. This means that it is stable even when the gyre is spun up, since the isohaline slope is always much smaller than the continental slope (Figs. 3c,d; Manucharyan and Isachsen 2019). Yet, Figs. 4 and 5 do show elevated levels of EKE on the slope, and Figs. 8 and 9 also reveal the generation of EKE there. Despite the stabilizing effect of the slope, the Eady theory might be too simple to fully capture the complexity of the interactions between the gyre and the slope. First, the continental slope around part of the gyre is so steep that the dynamical regime found here may not differ largely from the regime that we would expect with a vertical wall instead of a slope (as in Meneghello et al. 2018a). Second, Manucharyan and Isachsen (2019) note that the Eady theory ignores eddy momentum fluxes, whereas, in reality, barotropic instability acts over the slope to transport the momentum into the interior where baroclinic instability is then able to develop. Indeed, similar to the results of Manucharyan and Isachsen (2019), our model also exhibits higher transfer of MKE to EKE associated with barotropic instability over the continental slope (not shown).

Away from the continental slope, the response to the strong forcing anomaly in 2007 is different. Comparing the isohaline on the northern and western portions of the gyre against the southern and eastern portions, we find that the latter slopes are generally flatter (Fig. 3). The gyre is also strongly asymmetrical (Fig. 2b), so that the center of the gyre is closer to the side of the gyre constrained by the continental slope. Notably, the spinup of the gyre results in a stronger steepening of the isohalines in the southern and eastern portions. This is because they are bounded by bathymetry and therefore are restricted by the continental slope. In contrast, in the north and west, expansion relaxes the isohalines, reducing the potential for baroclinic instability and EKE generation compared to what would be expected from just an intensification of the gyre bounded by bathymetry everywhere. This expansion is most likely a response of the time and space variations of the Beaufort Sea high (Regan et al. 2019). Figure 10 shows the average sea level pressure in the region for the full time period, and the spinup and spun-up phases (note that this is not directly equivalent to the Ekman pumping field due to the modulation by sea ice and surface geostrophic currents, but the spatial pattern is broadly the same). In the spinup phase (Fig. 10b), the intensity is greatly increased, depressing isohalines within the gyre. In the spun-up phase (Fig. 10c), the Beaufort Sea high is extended to the north and greatly to the west compared to the 1990-2014 mean (Fig. 10a), resulting in a local depression of the isohalines to the north and west due to increased downwelling there, and thus reducing their steepness. Other effects such as changes in the lateral advection may also have 

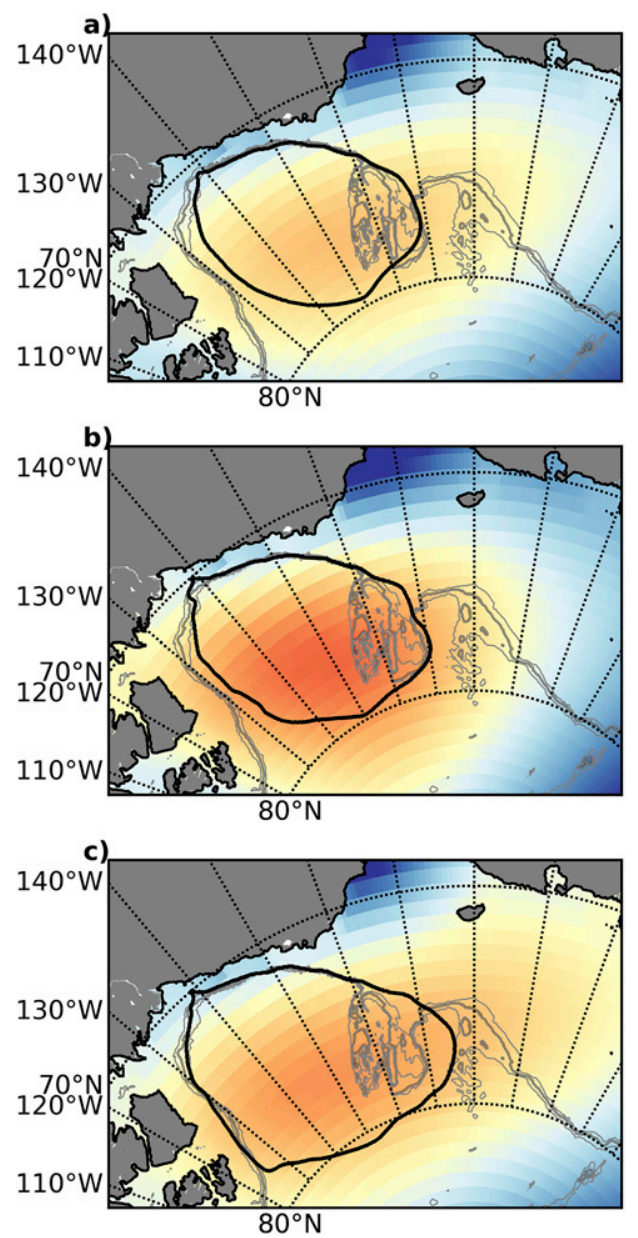

FIG. 10. Mean sea level pressure (hPa) from the DFS 5.2 atmospheric forcing dataset for (a) 1990-2014, (b) 2003-07 (spinup), and (c) 2008-14 (post-spinup). The average gyre contour over the respective years is shown in black. Bathymetry contours are shown at 500,1000 , and $1500 \mathrm{~m}$ in gray.

contributed to the expansion of the gyre, as discussed in Zhong et al. (2019a).

There are key differences between the realistic model used here and the previously used idealized models, in which the edge of the model domain-acting as a vertical wall-essentially marks the constant edge of the gyre, and the location of the surface forcing is held constant. This ability of the gyre to expand is an important mechanism by which the gyre is able to adjust to a change in Ekman pumping.

\section{Conclusions}

In this study, we have used a realistic high-resolution model to investigate the functioning of the Beaufort Gyre and its evolution over the period 1990-2014, which includes an observed period of strong spinup in response to changes in the atmospheric and sea ice conditions (Regan et al. 2019; Meneghello et al. 2018b). Previous studies, based on idealized models (Davis et al. 2014; Manucharyan and Spall 2016; Doddridge et al. 2019) or realistic low resolution models (Marshall et al. 2017) have suggested that such a spinup of the large scale gyre, driven by an increase in Ekman pumping, would be balanced by an increase in eddy flux that would arrest the steepening of the isohalines; some delay of the response might be expected due to the effect of the eddy memory (Manucharyan et al. 2017). This would also be consistent with the increase of the number of eddies found by Zhao et al. (2016) in 2013-14 compared to the previous decade in their ITP-based eddy survey, which could be an indication of intensified baroclinic instability in the southern portion of the gyre, although the limited number of eddies sampled questions the statistical significance of this finding.

Here the model allows us to describe the spatiotemporal evolutions of the total and eddy kinetic energy in the Canada Basin. In contrast to those previous results, we find that the gyre is able to spin up and sustain a higher level of mean kinetic energy that is generally not accompanied by higher levels of EKE. Two processes are invoked here to explain the discrepancies with the previous findings. On the southern side of the gyre, the presence of the continental slope tends to stabilize the gyre as suggested by Manucharyan and Isachsen (2019), so that the intensification of the mean current there only results in moderate enhanced levels of EKE. On the northern side of the gyre that is not directly constrained by bathymetry, the gyre is able to expand in response to an increase in Ekman pumping that extends to the northwest during and after the spinup, flattening the isohalines and thus limiting again the development of baroclinic instabilities. This, along with enhanced mean currents strengthening the ice-ocean governor, results in little increase in EKE after spinup. Indeed, on interannual time scales, the ice-ocean governor can dominate over EKE in equilibrating the gyre (Meneghello et al. 2020). These key ingredients, most likely important for the gyre equilibration, are currently not considered in most simple process models and should be included in future studies. The role of additional processes such as barotropic instabilities or dissipation through the effect of bottom drag may also be important here and should be investigated, as these have been shown to be important for the dynamical equilibrium of the Antarctic Circumpolar Current (e.g., Constantinou and Hogg 2019), which shares many similarities with the dynamics of the Beaufort Gyre.

Regardless of the link between its evolution and the gyre spinup, the EKE model fields exhibit some 
interesting features. When looking at our results, one needs to remember that our definition of EKE is based on an anomaly from the annual-mean currents, so that our EKE fields actually also account for the seasonal variations of the large-scale circulation, which are particularly pronounced in the boundary currents. Hence, our EKE fields are not only reflecting the presence of coherent eddies. Keeping these caveats in mind, we find that EKE is generally low in the ice-covered Arctic and of the same order of magnitude as the MKE, consistent with previous observations (e.g., Timmermans et al. 2012; Marcinko et al. 2015). This is because some of the key ingredients generating turbulence in the open ocean are missing: low net surface stress, due to a dampening of wind stress by sea ice, and high stratification lead to low levels of energy (Rainville and Woodgate 2009). Another Arctic-specific feature is the subsurface intensification of EKE. Indeed, in contrast to the surface where sea ice represents an additional source of dissipation for mesoscale eddies, eddies generated within the halocline will tend to survive longer (G. Meneghello et al. 2019, unpublished manuscript).

Our analysis also reveals that different time scales are important for the dynamics of the Beaufort Gyre and its adjustment. Some of the key parameters used here to describe the gyre, such as the position of the center, the intensity of the gyre or the freshwater content within the gyre, appear to respond gradually to changes in atmospheric forcing and sea ice conditions, with a gradual spinup occurring over 2003-07. This contrasts with the response to the anomalously strong downwelling that occurs throughout 2007 (Fig. 2g; Meneghello et al. 2018b), which forces a sharp increase in both the mean and eddy kinetic energy in the gyre in 2007. Yet, while the doubling in mean kinetic energy lasts after the return to normal atmospheric conditions after 2008, the level of EKE decreases again in 2008. In line with the study of Johnson et al. (2018) that suggested that the Arctic freshwater content holds a memory of the previous decade of atmospheric forcing, our results suggest that different features of the gyre can respond differently to long term trends and strong anomalous events in the atmospheric forcing, but also show that the gyre can retain a strong memory of extreme atmospheric events. The projected increase in Arctic storminess (e.g., Day et al. 2018) may thus have an impact on the large scale circulation in the Arctic.

Acknowledgments. We thank Helen Johnson, Anne Marie Tréguier, and Andy Hogg for valuable discussions at an early stage of this study. We also thank Pauline Tedesco for useful discussions on ocean energetics. We are grateful to Mike Spall and an anonymous reviewer for their comments which helped to improve the manuscript. The pan-Arctic simulation was performed using HPC resources from GENCI-CINES (Grant 2018-A0050107420). We acknowledge funding from the French LEFE/INSU program through the project FREDY, from the French ANR through the project ImMEDIAT (Grant ANR-18-CE01-0010), and from the MISTI Global Seeds Funds for the project "The Arctic in a Warming World." This work is also part of the ARKTALAS Hoavva study funded by the European Space Agency under the Contract 4000127401/19/NL/LF. G. M. acknowledges support from the NSF program in Arctic Research, through the Grant 1603557. The freshwater content data were collected and made available by the Beaufort Gyre Exploration Program based at the Woods Hole Oceanographic Institution (http://www.whoi.edu/beaufortgyre) in collaboration with researchers from Fisheries and Oceans Canada at the Institute of Ocean Sciences. Arctic dynamic topography data were provided by the Centre for Polar Observation and Modelling, University College London (www.cpom.ucl.ac.uk/dynamic_topography) (Armitage et al. 2016, 2017).

\section{REFERENCES}

Armitage, T. W. K., S. Bacon, A. L. Ridout, S. Thomas, Y. Aksenov, and D. J. Wingham, 2016: Arctic sea surface height variability and change from satellite radar altimetry and GRACE, 20032014. J. Geophys. Res. Oceans, 121, 4303-4322, https://doi.org/ 10.1002/2015JC011579.

- — - - - A. A. Petty, S. Wolbach, and M. Tsamados, 2017: Arctic Ocean surface geostrophic circulation 20032014. Cryosphere, 11, 1767-1780, https://doi.org/10.5194/tc11-1767-2017.

Arzel, O., T. Fichefet, H. Goosse, and J.-L. Dufresne, 2008: Causes and impacts of changes in the Arctic freshwater budget during the twentieth and twenty-first centuries in an AOGCM. Climate Dyn., 30, 37-58, https://doi.org/10.1007/s00382-007-0258-5.

Balwada, D., K. G. Speer, J. H. LaCasce, W. B. Owens, J. Marshall, and R. Ferrari, 2016: Circulation and stirring in the southeast Pacific Ocean and the Scotia Sea sectors of the Antarctic Circumpolar Current. J. Phys. Oceanogr., 46, 2005-2027, https://doi.org/10.1175/JPO-D-15-0207.1.

Barnier, B., and Coauthors, 2006: Impact of partial steps and momentum advection schemes in a global ocean circulation model at eddy-permitting resolution. Ocean Dyn., 56, 543567, https://doi.org/10.1007/s10236-006-0082-1.

Beckmann, A., C. W. Böning, B. Brügge, and D. Stammer, 1994: On the generation and role of eddy variability in the central North Atlantic Ocean. J. Geophys. Res., 99, 20381-20391, https://doi.org/10.1029/94JC01654.

Belkin, I. M., S. Levitus, J. Antonov, and S.-A. Malmberg, 1998: "Great salinity anomalies" in the North Atlantic. Prog. Oceanogr., 41, 168, https://doi.org/10.1016/S0079-6611(98)00015-9.

Bourgain, P., and J.-C. Gascard, 2011: The Arctic Ocean halocline and its interannual variability from 1997 to 2008. Deep-Sea Res. I, 58, 745-756, https://doi.org/10.1016/j.dsr.2011.05.001. 
Brannigan, L., H. Johnson, C. Lique, J. Nycander, and J. Nilsson, 2017: Generation of subsurface anticyclones at arctic surface fronts due to a surface stress. J. Phys. Oceanogr., 47, 2653 2671, https://doi.org/10.1175/JPO-D-17-0022.1.

Brodeau, L., B. Barnier, A.-M. Tréguier, T. Penduff, and S. K. Gulev, 2010: An ERA40-based atmospheric forcing for global ocean circulation models. Ocean Modell., 31, 88104, https://doi.org/10.1016/j.ocemod.2009.10.005.

Carmack, E. C., and Coauthors, 2016: Freshwater and its role in the Arctic Marine System: Sources, disposition, storage, export, and physical and biogeochemical consequences in the Arctic and global oceans. J. Geophys. Res. Biogeosci., 121, 675-717, https://doi.org/10.1002/2015JG003140.

Constantinou, N. C., and A. M. Hogg, 2019: Eddy saturation of the Southern Ocean: A baroclinic versus barotropic perspective. Geophys. Res. Lett., 46, 12 202-12 212, https://doi.org/10.1029/ 2019 GL084117.

Dai, A., and K. E. Trenberth, 2002: Estimates of freshwater discharge from continents: Latitudinal and longitudinal variations. J. Hydrometeor., 3, 660-687, https://doi.org/10.1175/ 1525-7541(2002)003<0660:EOFDFC $>2.0 . \mathrm{CO} ; 2$.

Davis, P. E. D., C. Lique, and H. L. Johnson, 2014: On the link between Arctic sea ice decline and the freshwater content of the Beaufort Gyre: Insights from a simple process model. J. Climate, 27, 8170-8184, https://doi.org/10.1175/JCLI-D-14-00090.1.

,,--- , and J. D. Guthrie, 2016: Competing effects of elevated vertical mixing and increased freshwater input on the stratification and sea ice cover in a changing arctic ocean. J. Phys. Oceanogr., 46, 1531-1553, https://doi.org/10.1175/ JPO-D-15-0174.1.

Day, J. J., M. M. Holland, and K. I. Hodges, 2018: Seasonal differences in the response of Arctic cyclones to climate change in CESM1. Climate Dyn., 50, 3885-3903, https://doi.org/ 10.1007/s00382-017-3767-x.

de Lavergne, C., S. Falahat, G. Madec, F. Roquet, J. Nycander, and C. Vic, 2019: Toward global maps of internal tide energy sinks. Ocean Modell., 137, 52-75, https://doi.org/10.1016/ j.ocemod.2019.03.010.

Dickson, R. R., J. Meincke, S.-A. Malmberg, and A. J. Lee, 1988: The "great salinity anomaly" in the northern North Atlantic 1968-1982. Prog. Oceanogr., 20, 103-151, https://doi.org/ 10.1016/0079-6611(88)90049-3.

Doddridge, E. W., G. Meneghello, J. Marshall, J. Scott, and C. Lique, 2019: A three-way balance in the Beaufort Gyre: The ice-ocean governor, wind stress, and eddy diffusivity. J. Geophys. Res. Oceans, 124, 3107-3124, https://doi.org/ 10.1029/2018JC014897.

Dupont, F., and Coauthors, 2015: A high-resolution ocean and seaice modelling system for the Arctic and North Atlantic oceans. Geosci. Model Dev., 8, 1577-1594, https://doi.org/10.5194/ gmd-8-1577-2015.

Eady, E. T., 1949: Long waves and cyclone waves. Tellus, 1, 33-52, https://doi.org/10.3402/tellusa.v1i3.8507.

Eden, C., and C. Böning, 2002: Sources of eddy kinetic energy in the Labrador Sea.J. Phys. Oceanogr., 32, 3346-3363, https://doi.org/ 10.1175/1520-0485(2002)032<3346:SOEKEI >2.0.CO;2.

Giles, K. A., S. W. Laxon, A. L. Ridout, D. J. Wingham, and S. Bacon, 2012: Western Arctic Ocean freshwater storage increased by wind-driven spin-up of the Beaufort Gyre. Nat. Geosci., 5, 194-197, https://doi.org/10.1038/ngeo1379.

Haine, T. W. N., and Coauthors, 2015: Arctic freshwater export: Status, mechanisms, and prospects. Global Planet. Change, 125, 13-35, https://doi.org/10.1016/j.gloplacha.2014.11.013.
Hogg, A. M., M. P. Meredith, D. P. Chambers, E. P. Abrahamsen, C. W. Hughes, and A. K. Morrison, 2015: Recent trends in the Southern Ocean eddy field. J. Geophys. Res. Oceans, 120, 257 267, https://doi.org/10.1002/2014JC010470.

$\mathrm{Hu}$, X., P. G. Myers, and Y. Lu, 2019: Pacific water pathway in the Arctic Ocean and Beaufort Gyre in two simulations with different horizontal resolutions. J. Geophys. Res. Oceans, 124, 6414-6432, https://doi.org/10.1029/2019JC015111.

Hunkins, K., 1981: Arctic Ocean eddies and baroclinic instability Tech. Rep. CU2-81, Lamont-Doherty Geol. Obs., 39 pp.

Jahn, A., and M. M. Holland, 2013: Implications of Arctic sea ice changes for North Atlantic deep convection and the meridional overturning circulation in CCSM4-CMIP5 simulations. Geophys. Res. Lett., 40, 1206-1211, https://doi.org/10.1002/ grl.50183.

Johnson, H. L., S. Cornish, Y. Kostov, E. Beer, and C. Lique, 2018: Arctic Ocean freshwater content and its decadal memory of sea-level pressure. Geophys. Res. Lett., 45, 4991-5001, https:// doi.org/10.1029/2017GL076870.

Krishfield, R. A., A. Proshutinsky, K. Tateyama, W. J. Williams, E. C. Carmack, F. A. McLaughlin, and M. L. Timmermans, 2014: Deterioration of perennial sea ice in the Beaufort Gyre from 2003 to 2012 and its impact on the oceanic freshwater cycle.J. Geophys. Res. Oceans, 119, 1271-1305, https://doi.org/ 10.1002/2013JC008999.

Le Traon, P. Y., 1991: Time scales of mesoscale variability and their relationship with space scales in the North Atlantic. J. Mar. Res., 49, 467-492, https://doi.org/10.1357/002224091784995828.

Lique, C., and H. L. Johnson, 2015: Is there any imprint of the wind variability on the Atlantic water circulation within the Arctic Basin? Geophys. Res. Lett., 42, 9880-9888, https://doi.org/ 10.1002/2015GL066141.

- - - and P. E. D. Davis, 2015: On the interplay between the circulation in the surface and the intermediate layers of the Arctic Ocean. J. Phys. Oceanogr., 45, 1393-1409, https:// doi.org/10.1175/JPO-D-14-0183.1.

—, M. M. Holland, Y. B. Dibike, D. M. Lawrence, and J. A. Screen, 2016: Modeling the Arctic freshwater system and its integration in the global system: Lessons learned and future challenges. J. Geophys. Res. Biogeosci., 121, 540-566, https:// doi.org/10.1002/2015JG003120.

Madec, G., 2016: NEMO ocean engine. Note du Pôle de modélisation de l'Institut Pierre-Simon Laplace 27, 386 pp., https://www.nemoocean.eu/wp-content/uploads/NEMO_book.pdf.

Manley, T. O., and K. Hunkins, 1985: Mesoscale eddies of the Arctic Ocean. J. Geophys. Res., 90, 4911-4930, https://doi.org/ 10.1029/JC090iC03p04911.

Manucharyan, G. E., and M. A. Spall, 2016: Wind-driven freshwater buildup and release in the Beaufort Gyre constrained by mesoscale eddies. Geophys. Res. Lett., 43, 273-282, https:// doi.org/10.1002/2015GL065957.

, and P. Isachsen, 2019: Critical role of continental slopes in halocline and eddy dynamics of the Ekman-driven Beaufort Gyre.J. Geophys. Res. Oceans, 124, 2679-2696, https://doi.org/ 10.1029/2018JC014624.

_ A. F. Thompson, and M. A. Spall, 2017: Eddy-Memory mode of multi-decadal variability in residual-mean ocean circulations with application to the Beaufort Gyre. J. Phys. Oceanogr., 47 855-866, https://doi.org/10.1175/JPO-D-16-0194.1.

Marcinko, C., A. P. Martin, and J. T. Allen, 2015: Characterizing horizontal variability and energy spectra in the Arctic Ocean halocline. J. Geophys. Res. Oceans, 120, 436-450, https:// doi.org/10.1002/2014JC010381. 
Marshall, J., J. Scott, and A. Proshutinsky, 2017: "Climate response functions" for the Arctic Ocean: A proposed coordinated modelling experiment. Geosci. Model Dev., 10, 2833-2848, https://doi.org/10.5194/gmd-10-2833-2017.

Maslowski, W., J. C. Kinney, D. C. Marble, and J. Jakacki, 2008: Towards eddy-resolving models of the Arctic Ocean. Ocean Modeling in an Eddying Regime, Geophys. Monogr., Vol. 177, Amer. Geophys. Union, 241-264.

McLaughlin, F. A., and E. C. Carmack, 2010: Deepening of the nutricline and chlorophyll maximum in the Canada Basin interior, 2003-2009. Geophys. Res. Lett., 37, L24602, https:// doi.org/10.1029/2010GL045459.

Meneghello, G., J. Marshall, S. T. Cole, and M.-L. Timmermans, 2017: Observational inferences of lateral eddy diffusivity in the halocline of the Beaufort Gyre. Geophys. Res. Lett., 44, 12 331-12 338, https://doi.org/10.1002/2017GL075126.

_, J.-M. Campin, E. Doddridge, and M.-L. Timmermanns, 2018a: The ice-ocean governor: Ice-ocean stress feedback limits Beaufort Gyre spinup. Geophys. Res. Lett., 45, 11293 11299, https://doi.org/10.1029/2018GL080171.

,,-- M.-L. Timmermans, and J. Scott, 2018b: Observations of seasonal upwelling and downwelling in the Beaufort Sea mediated by sea ice. J. Phys. Oceanogr., 48, 795-805, https:// doi.org/10.1175/JPO-D-17-0188.1.

_ E. Doddridge, J. Marshall, J. Scott, and J.-M. Campin, 2020: Exploring the role of the "ice-ocean governor" and mesoscale eddies in the equilibration of the Beaufort Gyre: Lessons from observations. J. Phys. Oceanogr., 50, 269-277, https://doi.org/ 10.1175/JPO-D-18-0223.1.

Newton, J. L., K. Aagaard, and L. K. Coachman, 1974: Baroclinic eddies in the Arctic Ocean. Deep-Sea Res. Oceanogr. Abstr., 21, 707-719, https://doi.org/10.1016/0011-7471(74)90078-3.

Nurser, A. J., and S. Bacon, 2014: The Rossby radius in the Arctic Ocean. Ocean Sci., 10, 967-975, https://doi.org/10.5194/ os-10-967-2014.

Ou, H. W., and A. L. Gordon, 1986: Spin-down of baroclinic eddies under sea ice. J. Geophys. Res., 91, 7623-7630, https://doi.org/ 10.1029/JC091iC06p07623.

Pickart, R. S., 2004: Shelfbreak circulation in the Alaskan Beaufort Sea: Mean structure and variability. J. Geophys. Res., 109, C04024, https://doi.org/10.1029/2003JC001912.

__ M. A. Spall, and J. T. Mathis, 2013: Dynamics of upwelling in the Alaskan Beaufort Sea and associated shelf-basin fluxes. Deep-Sea Res. I, 76, 35-51, https://doi.org/10.1016/ j.dsr.2013.01.007.

Plueddemann, A. J., R. Krishfield, T. Takizawa, K. Hatakeyama, and S. Honjo, 1998: Upper ocean velocities in the Beaufort Gyre. Geophys. Res. Lett., 25, 183-186, https://doi.org/10.1029/ 97GL53638.

Polyakov, I. V., A. V. Pnyushkov, and E. C. Carmack, 2018: Stability of the arctic halocline: A new indicator of arctic climate change. Environ. Res. Lett., 13, 125008, https://doi.org/ 10.1088/1748-9326/AAEC1E.

Proshutinsky, A., and Coauthors, 2009: Beaufort Gyre freshwater reservoir: State and variability from observations. J. Geophys. Res., 114, C00A10, https://doi.org/10.1029/2008JC005104.

—_, D. Dukhovskoy, M.-L. Timmermanns, R. Krishfield, and J. Bamber, 2015: Arctic circulation regimes. Philos. Trans. Roy. Soc. A, 373, 20140160, https://doi.org/10.1098/ rsta.2014.0160.

- , and Coauthors, 2020: Analysis of the Beaufort Gyre freshwater content in 2003-2018. J. Geophys. Res. Oceans, 124, 9658-9689, https://doi.org/10.1029/2019JC015281.
Rainville, L., and R. A. Woodgate, 2009: Observations of internal wave generation in the seasonally ice-free Arctic. Geophys. Res. Lett., 36, L23604, https://doi.org/10.1029/2009GL041291.

Regan, H. C., C. Lique, and T. W. K. Armitage, 2019: The Beaufort Gyre extent, shape, and location between 2003 and 2014 from satellite observations. J. Geophys. Res. Oceans, 124, 844-862, https://doi.org/10.1029/2018JC014379.

Richardson, P. L., 1983: A vertical section of eddy kinetic energy through the Gulf Stream system. J. Geophys. Res., 88, 27052709, https://doi.org/10.1029/JC088iC04p02705.

Rieck, J. K., C. W. Böning, R. J. Greatbatch, and M. Scheinert, 2015: Seasonal variability of eddy kinetic energy in a global high-resolution ocean model. Geophys. Res. Lett., 42, 93799386, https://doi.org/10.1002/2015GL066152.

- — , and — 2018: Decadal variability of eddy kinetic energy in the South Pacific subtropical countercurrent in an ocean general circulation model. J. Phys. Oceanogr., 48, 757771, https://doi.org/10.1175/JPO-D-17-0173.1.

Rousset, C., and Coauthors, 2015: The Louvain-La-Neuve sea ice model LIM3.6: Global and regional capabilities. Geosci. Model Dev., 8, 2991-3005, https://doi.org/10.5194/gmd-8-29912015.

Schmidtko, S., G. C. Johnson, and J. M. Lyman, 2013: MIMOC: A global monthly isopycnal upper-ocean climatology with mixed layers. J. Geophys. Res. Oceans, 118, 1658-1672, https:// doi.org/10.1002/jgrc.20122.

Serreze, M. C., and A. P. Barrett, 2011: Characteristics of the Beaufort Sea high. J. Climate, 24, 159-182, https://doi.org/ 10.1175/2010JCLI3636.1.

Shimada, K., M. Itoh, S. Nishino, F. McLaughlin, E. Carmack, and A. Proshutinsky, 2005: Halocline structure in the Canada Basin of the Arctic Ocean. Geophys. Res. Lett., 32, L03605, https://doi.org/10.1029/2004GL021358.

Spall, M., 2000: Generation of strong mesoscale eddies by weak ocean gyres. J. Mar. Res., 58, 97-116, https://doi.org/10.1357/ 002224000321511214

Spall, M. A., R. S. Pickart, P. S. Fratantoni, and A. J. Plueddemann, 2008: Western Arctic shelfbreak eddies: Formation and transport. J. Phys. Oceanogr., 38, 1644-1668, https://doi.org/ 10.1175/2007JPO3829.1.

,-- M. Li, M. Itoh, P. Lin, T. Kikuchi, and Y. Qi, 2018: Transport of Pacific water into the Canada Basin and the formation of the Chukchi slope current. J. Geophys. Res. Oceans, 123, 7453-7471, https://doi.org/10.1029/2018JC013825.

Timmermans, M.-L., J. Toole, A. Proshutinsky, R. Krishfield, and A. Plueddemann, 2008: Eddies in the Canada Basin, Arctic Ocean, observed from ice-tethered profilers. J. Phys. Oceanogr., 38, 133-145, https://doi.org/10.1175/2007JPO3782.1.

— S. Cole, and J. Toole, 2012: Horizontal density structure and restratification of the Arctic Ocean surface layer. J. Phys. Oceanogr., 42, 659-668, https://doi.org/10.1175/JPO-D-11-0125.1.

__ and Coauthors, 2014: Mechanisms of Pacific summer water variability in the Arctic's Central Canada Basin. J. Geophys. Res., 119, 7523-7548, https://doi.org/10.1002/ 2014JC010273.

Toole, J., R. Krishfield, M.-L. Timmermans, and A. Proshutinsky, 2011: The ice-tethered profiler: Argo of the Arctic. Oceanography, 24, 126-135, https://doi.org/10.5670/oceanog.2011.64.

Tréguier, A.-M., and Coauthors, 2014: Meridional transport of salt in the global ocean from an eddy-resolving model. Ocean Sci., 10, 243-255, https://doi.org/10.5194/os-10-243-2014.

Trodahl, M., and P. E. Isachsen, 2018: Topographic influence on baroclinic instability and the mesoscale eddy field in the 
Northern North Atlantic Ocean and the Nordic Seas. J. Phys. Oceanogr., 48, 2593-2607, https://doi.org/10.1175/JPO-D-170220.1.

von Appen, W.-J., and R. S. Pickart, 2012: Two configurations of the Western Arctic shelfbreak current in summer. J. Phys. Oceanogr., 42, 329-351, https://doi.org/10.1175/JPO-D-11026.1 .

von Storch, J. S., C. Eden, I. Fast, H. Haak, D. Hernández, E. Maier-Reimer, J. Marotzke, and D. Stammer, 2012: An estimate of the Lorenz energy cycle for the World Ocean based on the STORM/NCEP simulation. J. Phys. Oceanogr., 42, 2185-2205, https://doi.org/10.1175/JPO-D-12-079.1.

Wang, Q., and Coauthors, 2016: An assessment of the arctic ocean in a suite of interannual core-II simulations. Part II: Liquid freshwater. Ocean Modell., 99, 86-109, https://doi.org/10.1016/ j.ocemod.2015.12.009.

Watanabe, E., and H. Hasumi, 2009: Pacific water transport in the Western Arctic Ocean simulated by an eddy-resolving coupled sea ice-ocean model. J. Phys. Oceanogr., 39, 2194-2211, https://doi.org/10.1175/2009JPO4010.1.

— marine biological pump. Nat. Commun., 5, 3950, https:// doi.org/10.1038/ncomms4950.

Winters, K. B., P. N. Lombard, J. J. Riley, and E. A. D'Asaro, 1995: Available potential energy and mixing in density-stratified fluids. J. Fluid Mech., 289, 115-128, https://doi.org/10.1017/ S002211209500125X.

Woodgate, R. A., K. M. Stafford, and F. G. Prahl, 2015: A synthesis of year-round interdisciplinary mooring measurements in the Bering Strait (1990-2014) and the RUSALCA years (2004-2011). Oceanography, 28, 46-67, https://doi.org/ 10.5670/oceanog.2015.57.
Wunsch, C., 2002: Ocean observations and the climate forecast problem. Meteorology at the Millennium, R. Pearce, Ed., International Geophysics Series, Vol. 83, Academic Press, 233-245.

Zhai, X., R. J. Greatbatch, and J.-D. Kohlmann, 2008: On the seasonal variability of eddy kinetic energy in the Gulf Stream region. Geophys. Res. Lett., 35, L24609, https://doi.org/ 10.1029/2008GL036412.

Zhang, J., and Coauthors, 2016: The Beaufort Gyre intensification and stabilization: A model-observation synthesis. J. Geophys. Res. Oceans, 121, 7933-7952, https://doi.org/ 10.1002/2016JC012196.

Zhang, Z., J. Tian, B. Qiu, W. Zhao, P. Chang, D. Wu, and X. Wan 2016: Observed 3D structure, generation, and dissipation of oceanic mesoscale eddies in the South China Sea. Sci. Rep., 6, 24349, https://doi.org/10.1038/srep24349.

Zhao, M., M. L. Timmermans, S. Cole, R. Krishfield, A. Proshutinsky, and J. Toole, 2014: Characterizing the eddy field in the Arctic Ocean halocline. J. Geophys. Res. Oceans, 119, 8800-8817, https://doi.org/10.1002/2014JC010488.

,,,,---- and J. Toole, 2016: Evolution of the eddy field in the Arctic Ocean's Canada Basin, 2005-2015. Geophys. Res. Lett., 43, 8106-8114, https://doi.org/10.1002/2016GL069671.

Zhong, W., M. Steele, J. Zhang, and S. T. Cole, 2019a: Circulation of Pacific winter water in the Western Arctic Ocean. J. Geophys. Res. Oceans, 124, 863-881, https:// doi.org/10.1029/2018JC014604.

_, J. Zhang, M. Steele, J. Zhao, and T. Wang, 2019b: Episodic extrema of surface stress energy input to the Western Arctic Ocean contributed to step changes of freshwater content in the Beaufort Gyre. Geophys. Res. Lett., 46, 12 173-12 182, https:// doi.org/10.1029/2019GL084652. 